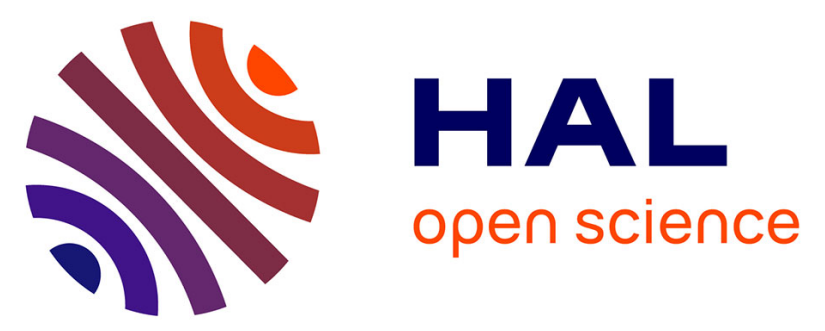

\title{
Pollen-based reconstruction of Holocene land-cover in mountain regions: Evaluation of the Landscape Reconstruction Algorithm in the Vicdessos valley, northern Pyrenees, France
}

Laurent Marquer, Florence Mazier, Shinya Sugita, Didier Galop, Thomas Houet, Élodie Faure, Marie-José Gaillard, Sébastien Haunold, Nicolas de Munnik, Anaëlle Simonneau, et al.

\section{- To cite this version:}

Laurent Marquer, Florence Mazier, Shinya Sugita, Didier Galop, Thomas Houet, et al.. Pollen-based reconstruction of Holocene land-cover in mountain regions: Evaluation of the Landscape Reconstruction Algorithm in the Vicdessos valley, northern Pyrenees, France. Quaternary Science Reviews, 2020, 228, pp.106049. 10.1016/j.quascirev.2019.106049 . insu-02418207

\section{HAL Id: insu-02418207 https://hal-insu.archives-ouvertes.fr/insu-02418207}

Submitted on 10 Jul 2020

HAL is a multi-disciplinary open access archive for the deposit and dissemination of scientific research documents, whether they are published or not. The documents may come from teaching and research institutions in France or abroad, or from public or private research centers.
L'archive ouverte pluridisciplinaire HAL, est destinée au dépôt et à la diffusion de documents scientifiques de niveau recherche, publiés ou non, émanant des établissements d'enseignement et de recherche français ou étrangers, des laboratoires publics ou privés. 


\section{$1 \quad$ Highlights}

2 - Pollen-based reconstruction of Holocene land-cover in mountain regions

3 - The LRA approach is effective in mountain regions

4 - The REVEALS-based estimates are influenced by the systematic selection of pollen sites

5 - Pollen proportions alone are not useful for the local reconstruction

6 - New horizons for answering questions about human impact on upland vegetation 


\section{Landscape Reconstruction Algorithm in the Vicdessos valley, Northern Pyrenees, France}

3

4

5 Laurent Marquer ${ }^{\mathrm{a}, \mathrm{b}, \mathrm{c}^{*}}$, Florence Mazier ${ }^{\mathrm{b}}$, Shinya Sugita ${ }^{\mathrm{d}}$, Didier Galop ${ }^{\mathrm{b}}$, Thomas Houet ${ }^{\mathrm{e}}$, Elodie

6 Faure $^{\mathrm{b}}$, Marie-José Gaillard ${ }^{\mathrm{f}}$, Sébastien Haunold ${ }^{\mathrm{a}, \mathrm{b}}$, Nicolas de Munnik ${ }^{\mathrm{b}}$, Anaëlle Simonneau ${ }^{\mathrm{g}}$, 7 François De Vleeschouwer a,h, Gaël Le Roux ${ }^{\text {a }}$

8

9

10

11

(France), $\quad$ laurent.marquer.es@gmail.com;

francois.devleeschouwer@ensat.fr;

gael.leroux@ensat.fr;

12 sebastien.haunold@ensat.fr

13

14

15

16

17

1.marquer@mpic.de

18

19

20

21

lemdahl@lnu.se

22

23

b GEODE, UMR-CNRS 5602, Labex DRIIHM (OHM Pyrénées Haut Vicdessos), Université Toulouse Jean Jaurès (France), $\quad$ florence.mazier@univ-tlse2.fr; $\quad$ elo faure@yahoo.fr; $\quad$ nicolas.demunnik@univ-tlse2.fr;

didier.galop@,univ-tlse2.fr

c Research Group for Terrestrial Palaeoclimates, Max Planck Institute for Chemistry, Mainz (Germany),

d Institute of Ecology, Tallinn University (Estonia), sugita@tlu.ee

e LETG-Rennes COSTEL, UMR 6554 CNRS, Université Rennes 2 (France), thomas.houet@univ-rennes2.fr

${ }^{\mathrm{f}}$ Department of Biology and Environmental Science, Linnaeus University (Sweden), marie-jose.gaillardg OSUC, Observatoire des Sciences de l'Univers en région Centre, Université d'Orléans (France), anaelle.simonneau@univ-orleans.fr 
$24{ }^{\mathrm{h}}$ Instituto Franco-Argentino para el Estudio del Clima y sus Impactos (UMI IFAECI/CNRS-CONICET-UBA-

25 IRD), Dpto. de Ciencias de la Atmosfera y los Oceanos, FCEN, Universidad de Buenos Aires, Argentina,

26 ddevleeschouwer@cima.fcen.uba.ar

27

28

$29 *$ Corresponding author:

30 Laurent Marquer

31 E-mail: laurent.marquer.es@gmail.com; 1.marquer@mpic.de 

Long-term perspectives on climate- and human-induced shifts in plant communities and tree line in mountains are often inferred from fossil pollen records. However, various factors, such as complex patterns of orographic wind fields and abundant insect-pollinated plants in higher altitudes, make pollen-based reconstruction in mountain regions difficult. approach in reconstruction of vegetation - has been successfully applied in various parts of the globe. However, evaluation of its effectiveness in mountain ranges is still limited. The present study assesses the extent to which the LRA approach helps quantify the local changes in vegetation cover at Vicdessos valley in northern French Pyrenees as a case study. In the study area well-dated sediment cores are available from eight bogs and ponds, $6-113 \mathrm{~m}$ in radius, located above the current tree line. We first use a simple simulation experiment to evaluate the way how pollen records from "landscape islands" (mountain tops and plateaus) would represent local vegetation and to clarify important factors affecting the LRA-based reconstruction in a mountainous region. This study then uses pollen records from these sites and vegetation and land-cover data both within a 50-km radius around the Vicdessos valley and within a 2-km radius from each site for evaluation of the REVEALSand LOVE-based reconstruction of the regional and local plant cover, respectively, in the LRA approach. The land-cover data are complied for coniferous trees, broadleaved trees and non-forested 
51 areas from the CORINE and historical maps in three time windows: 1960-1970, 1990-2000 and 2000-

522013.

53

Major findings are as follows. (1) Accuracy of the regional vegetation estimates affects the

54 reliability of the LRA-based reconstruction of vegetation within a 2-km radius; use of the CORINE

55 data as input to the LOVE model improves reliability of the results over the use of the REVEALS-

56 based estimates of regional vegetation. This implies that a systematic selection of pollen data only

57 from sites above the tree line is problematic for estimating regional vegetation, and thus the entire

58 LRA process. (2) Selection of the dispersal models for pollen transport (i.e. the Langrangian

59 Stochastic Model vs. Gaussian Plume Model) does not affect significantly the LRA-based estimates

60 at both the regional and local scales in the study area. (3) The LRA approach improves the pollen-

61 based reconstruction of local vegetation compared to pollen percentage alone in northern Pyrenees.

62 Although further empirical and simulation studies are necessary, our results emphasize the

63 importance of site selection for the LRA-based reconstruction of vegetation in mountain regions.

65 Keywords Vegetation, Land use, Landscape, Open land, REVEALS, LOVE, Holocene, France 
Mountain landscapes in Europe are expected to change significantly over the next few decades

71 because of the ongoing climate change and reforestation caused by the abandonment of agro-pastoral areas (IPCC, 2014). These human-induced changes in climate and land cover will affect undoubtedly species composition and spatial dynamics of plant communities on mountains, including altitudinal

74 shifts in tree lines (Leunda et al., 2019). All those expected changes in mountain regions will impact on a large range of ecosystem services, including tourism, recreation, water resources (Szczypta et al., 2015) and loss of traditional land-use. deforestation) since the Bronze Age (Galop et al., 2013) and have undergone major transformations during the last century. Owing to rural depopulation, traditional pastoral management has declined since the 1950s (MacDonald et al., 2000). The history of the Vicdessos area in northeastern Pyrenees

81 is closely related to this progressive depopulation and the associated abandonment of former management practices. This has led to fast reforestation of the slopes and replacement of pastoral uplands by forests and heathlands (Houet et al., 2012, 2015; Vacquié et al., 2016), as in many

84 European mountains (Kozak et al., 2017). This has further resulted in a loss of plant diversity (Galop

85 et al., 2011) and insect species richness (e.g. hoverflies) in an adjacent valley (Herrault et al., 2016).

86 Those baseline information on the past mountain landscapes are critical to evaluate the effects of 
87 current and future land-use changes on high altitude ecosystems, biodiversity and for sustainable

88 land-management strategies.

Fossil pollen records have provided information on the century- to millennium-scale changes

in the past land cover. However, interpretation of pollen data is tricky in mountain regions because

91 of the complex physical and biological conditions and factors that influence the pollen-vegetation

relationships in unknown ways (e.g. Ortu et al., 2006; Leunda et al., 2017; Zhang et al., 2017). There phenology between mountains and lowlands, especially flowering timing of plants of the same species, make interpretation of pollen records difficult (Fall, 1992; Leunda et al., 2017). 4) Insectpollinated plants - the dominant type of plants in alpine zones - tend to be low pollen-producers, thus biasing pollen representation of vegetation (Markgraf, 1980; Fall, 1992). 5) Wind gradients and directions are often site-specific in mountains, thus it is difficult to generalize what pollen records 
often use both macro-remains of plants and pollen for reconstruction of the local- to landscape-scale

106 changes in mountain plant communities (e.g. Birks and Birks, 2000; Leunda et al., in press).

The present study aims to explore applicability of modeling approaches that overcome some

of these difficult issues and evaluate the extent to which models help to improve the interpretation of

pollen records in mountain regions. In the next section we first explore feasibility of the Landscape

Reconstruction Algorithm (LRA; Sugita, 2007a, 2007b) - a two-step model-based reconstruction

approach - for mountain vegetation, using simple simulations based on the POLLSCAPE models insights into the LRA applicability from the simulations at hand, the rest of this paper evaluates empirically the applicability and reliability of the LRA approach around the Vicdessos valley in the Pyrenees. The study area is well suited for this study, because (1) well-dated pollen records from eight sites are available at and above the tree line, and (2) the regional- and local-scale land-cover maps are available in three time periods (i.e., 1960-1970, 1990-2000 and 2000-2013) for comparison with the pollen-based reconstruction of the past land cover. Major assumptions and current important 
123 issues related to the LRA are described in detail in the method section, Appendix A and wherever

appropriate. We then discuss pros and cons of the LRA-based reconstruction in mountains and

125

126

127

128

address future directions to improve the approach.

\section{FEASIBILITY OF LRA-BASED RECONSTRUCTION OF VEGETATION IN}

\section{MOUNTAIN REGIONS: EVALUATION WITH SIMULATED LANDSCAPES}

Besides the complex nature of the wind field on mountains and juxtaposition of plant communities within short distances along short elevational gradients, a systematic selection of sites

restricted only to mountain tops and plateaus also potentially biases pollen representation of vegetation, thus affecting the accuracy of the LRA. It is a common practice to select pollen sites located only in sub-alpine or alpine zones because of the availability of sediments free from humanrelated disturbances (Simonneau et al., 2013). This site-selection scheme would influence the evaluation of long-distance pollen from lower altitudes - an important step for objective reconstruction of local vegetation on mountains (Sugita, 2007a,b).

The current section uses the POLLSCAPE approach (sensu Sugita, 2013) to evaluate the extent to which this site-selection scheme would affect the entire LRA process. In the POLLSCAPE simulations we regard mountain tops and high-altitude plateaus as "landscape islands" on a flat twodimensional terrain, $80 \mathrm{~km}$ x $80 \mathrm{~km}$ in size, for the sake of simplicity (as in Sugita, 1994; Sugita et 
141 al., 1997, 1999; Bunting et al., 2004; Broström et al., 2004, 2005; Gaillard et al., 2008; Hjelle and

142 Sugita, 2012). Although generalized, the simulated landscapes depict the characteristics of the spatial

143 structure and species composition of plant communities in high-altitude plateaus and the regional

144 vegetation around the Vicdessos valley (see section 3.1.). Figure 1a illustrates the general scheme of

145 the simulated landscapes with randomly located patches of specific plant-community types within

146 the Matrix. Seven plant/pollen types are included for simulations: Betula, Calluna, Ericaceae, Fagus,

147 Quercus, Poaceae and Pinus. The Matrix and Patch Type B represent plant communities in lower

148 altitudes in mountain valleys and flat plains, characterized by forests of mixed broadleaved and

149 conifer trees (Fagus, Quercus and Pinus) and grass (Poaceae)-dominated open areas, respectively.

150 Patch Type A symbolizes mountain tops that are characterized by Ericaceae plants (including

151 Rhododendron spp. and Vaccinium spp.) with semi-dominant grass and Calluna (heather). In Patch

152 Type A, small-patches of two types of heather heathlands are placed to fine-tune the local spatial

153 structure of vegetation: Patch Type C with heather, grass and Ericaceae and Patch Type D with

154 heather, grass, Ericaceae and Pinus.

The LRA consists of two steps: the first to estimate regional vegetation within $<50-100 \mathrm{~km}$

with the REVEALS model and the second to reconstruct the local- and landscape-scale changes in 
159 For either REVEALS or LOVE calculation, one of the patches of Patch Type A is selected randomly

160 in the central part of the plot, and a lake is placed within the area of the patch. For REVEALS

161 applications a lake 500-m in radius is placed at the center of the patch selected, and for LOVE

162 applications a lake 50-m in radius is located randomly within the patch. In each simulation run, we

163 repeat this process thirty times to obtain pollen counts from 30 lakes for REVEALS and LOVE,

164 separately. Pollen loading on lakes, with which pollen counts are simulated, is calculated by Sugita's

165 model for pollen deposition on lakes (Sugita, 1993). Pollen transport in air is approximated by both

166 a Gaussian Plume model (GPM) (Prentice, 1985; Sugita, 1993, 1994, 2007a, 2007b) and a Lagrangian

167 Stochastic model (LSM) of Kuparinen et al. (2007) and Theuerkauf et al. (2013, 2016). Pollen

168 productivity estimates - important parameters for the pollen loading calculation - are after Mazier et

169 al. (2012). We assume that the simulated pollen records are independently obtained at each site. These

170 records are used as inputs for the LRA-based reconstruction of vegetation around each site. The

171 LOVE results are expressed as area proportions within the RSAP for three categories: conifers (i.e.

172 Pinus), broadleaved trees (i.e. Betula, Quercus and Fagus) and open land (i.e. Poaceae, Calluna and

173 Ericaceae); by definition all the LOVE results are expressed in a distance-weighted fashion (Distance

174 Weighted Plant Abundance: DWPA) (Sugita, 2007b; Sugita et al., 2010). Appendix A provides a

175 brief description and sets of parameters necessary for the POLLSCAPE simulations and the LRA calculation. 
178 the RSAP. The LRA approach improves the accuracy of vegetation reconstruction significantly over

179 the pollen proportions alone. Considering the standard errors, the reconstructed values are not 180 significantly different from the 1:1 line along the two axes. Note that the standard errors of the open 181 land category are large, suggesting large uncertainties to be expected in reconstruction of the local 182 open land. The selection of the different dispersal models of pollen did not cause large differences in 183 the LRA-based reconstruction of the local vegetation. The inverse modelling of LOVE (Sugita, 184 2007b; Sugita et al., 2010) demonstrates that the RSAP is consistent in the simulations regardless of 185 the pollen dispersal models employed; the RSAP is within $310 \mathrm{~m}$ and $325 \mathrm{~m}$ with the GPM and LSM 186 options, respectively. With the LSM option, the variation in vegetation reconstruction among sites, 187 as well as the standard error estimate at each site, appears larger than that with the GPM option for 188 the three categories of land cover. 


\section{a) Simulated mountain landscape}

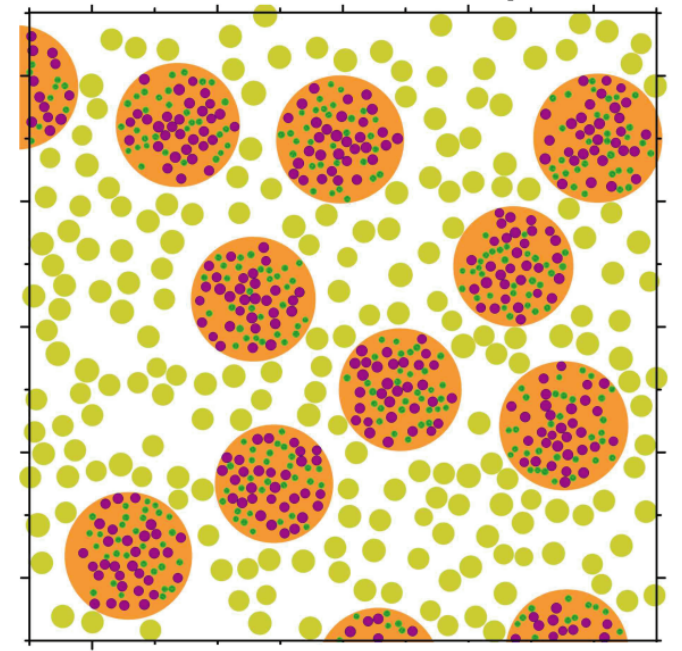

Matrix: mixed broadleaved and conifer trees

Patch A: Ericaceae with semi-dominant grass and heather

Patch B: grass-dominate unforested areas

Patch C: heather, grass and Ericaceae

Patch D: heather, grass, Ericaceae and pine

\section{b) Comparison pollen estimates versus DWPA based on simulated mountain landscape}
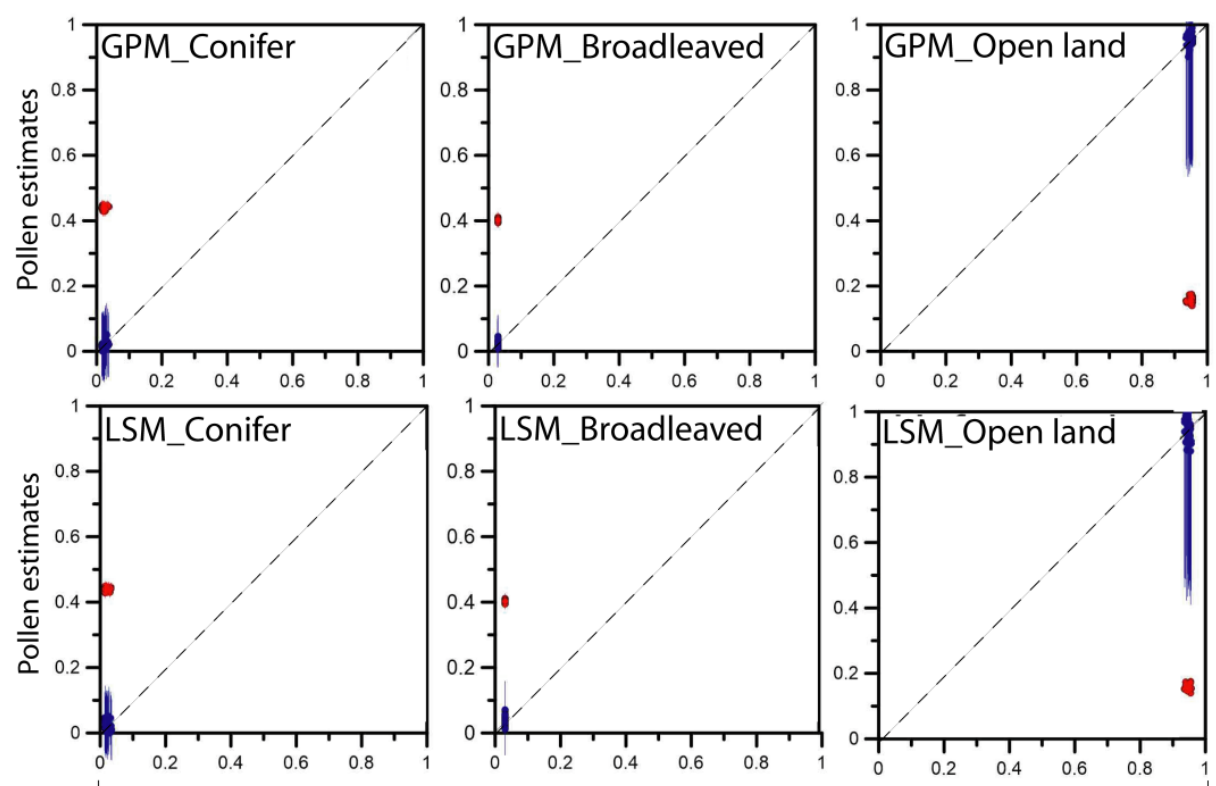

DWPA-based vegetation proportion

Figure 1a) Simulated mountain landscape that mimics the one of the Vicdessos valley to estimate pollen loadings on 30 lakes systematically located on mountain tops and plateaus. Mountain tops and plateaus correspond to Patch type A that includes two small patch types (Patch types C and D) of heather heathlands. The Matrix and Patch type B represent plant communities in lower altitudes in mountain valleys and flat plains. The simulated study plot is of $80 \mathrm{~km}$ x $80 \mathrm{~km}$. More details about the simulation are given in the text and Appendix A. b) Results of LRA comparing distance weighted plant abundance (DWPA) based on observed vegetation (i.e. landscape design around each lake) against pollen proportion (untransformed pollen data; red dots) and two sets of LRA estimates (blue dots), one using GPM and the other LSM as pollen dispersal model. Each point represents a pollen record from each lake. Pollen proportion and LRA estimates are reasonable representation of observed vegetation when pollen records are close to the dashed line. Standard errors are also shown. 
vegetation in mountain regions such as in the Pyrenees.

(1) Accuracy of the regional estimates of vegetation and land cover matters for reliable LRA

applications in mountains as in any other regions. Ideally, the REVEALS application requires pollen

records from randomly-selected sites $>100$ ha in both mountains and lowland areas in the region of

interest. It is hard to achieve this scenario in reality, however. The simulation results suggest that, as 1b); if only small sites $50 \mathrm{~m}$ in radius are used, we expect larger uncertainties for the regional estimates, resulting in less reliable LRA outcomes (Appendix A).

(2) Differences in the LRA results between using the GMP and LSM as a pollen dispersal model appear negligible in the simulation runs. Recent studies have shown that the LSM option produces more realistic results in REVEALS-based reconstruction of regional vegetation, especially for plants with heavy and light pollen types (Theuerkauf et al., 2013, 2016; Mariani et al., 2017) than the GPM option does. Considering more advanced understanding of wind field and particle transport in air (Kuparinen et al. 2007), the LSM option has advantages over the GPM option, especially for 
describing long-distance pollen from regional sources. As the simulation results (Figure 1b) suggest,

221 however, consistency in dispersal-model selection for REVEALS and LOVE in the LRA process

222 helps provide robust LRA estimates for reconstruction of the local- to landscape-scale vegetation in

223 spatially and topographically complex terrains (e.g. Hjelle et al., 2015).

\section{MATERIALS AND METHODS}

\subsection{Geographical setting, site characteristics and pollen data collection} in radius for lakes (Table 1). annual precipitation about $1640 \mathrm{~mm}$ (Quintana-Seguí et al., 2008). Snow season generally starts in 
Table 1 Metadata of the pollen archives.

\begin{tabular}{ccccccc}
\hline Site name & Lat.DD & Long.DD & $\begin{array}{c}\text { Elevation } \\
\mathbf{( m )}\end{array}$ & $\begin{array}{c}\text { Site } \\
\text { radius } \\
\mathbf{( m )}\end{array}$ & $\begin{array}{c}\text { Basin } \\
\text { type }\end{array}$ & $\begin{array}{c}\text { Age/depth model } \\
\text { and dating }\end{array}$ \\
\hline Sigriou (SIG) & 42.754 & 1.422 & 2000 & 66 & Lake & Simonneau et al. (2013) \\
Legunabens (LEG) & 42.764 & 1.431 & 1680 & 58 & Lake & Appendix B \\
Arbu (ARBU) & 42.821 & 1.437 & 1740 & 113 & Lake & Appendix B \\
Escale (ESC) & 42.761 & 1.430 & 1630 & 40 & Bog & Hansson et al. (2017) \\
Fouzes (FOUZ) & 42.766 & 1.410 & 1720 & 13 & Bog & Appendix B \\
W1652a (W1652) & 42.763 & 1.416 & 1660 & 6 & Bog & Hansson et al. (2017) \\
Etang Mort (EM) & 42.766 & 1.419 & 1670 & 36 & Bog & Hansson et al. (2017) \\
Orry de Théo (OT) & 42.766 & 1.415 & 1680 & 31 & Bog & Galop et al. (2011) \\
\hline
\end{tabular}

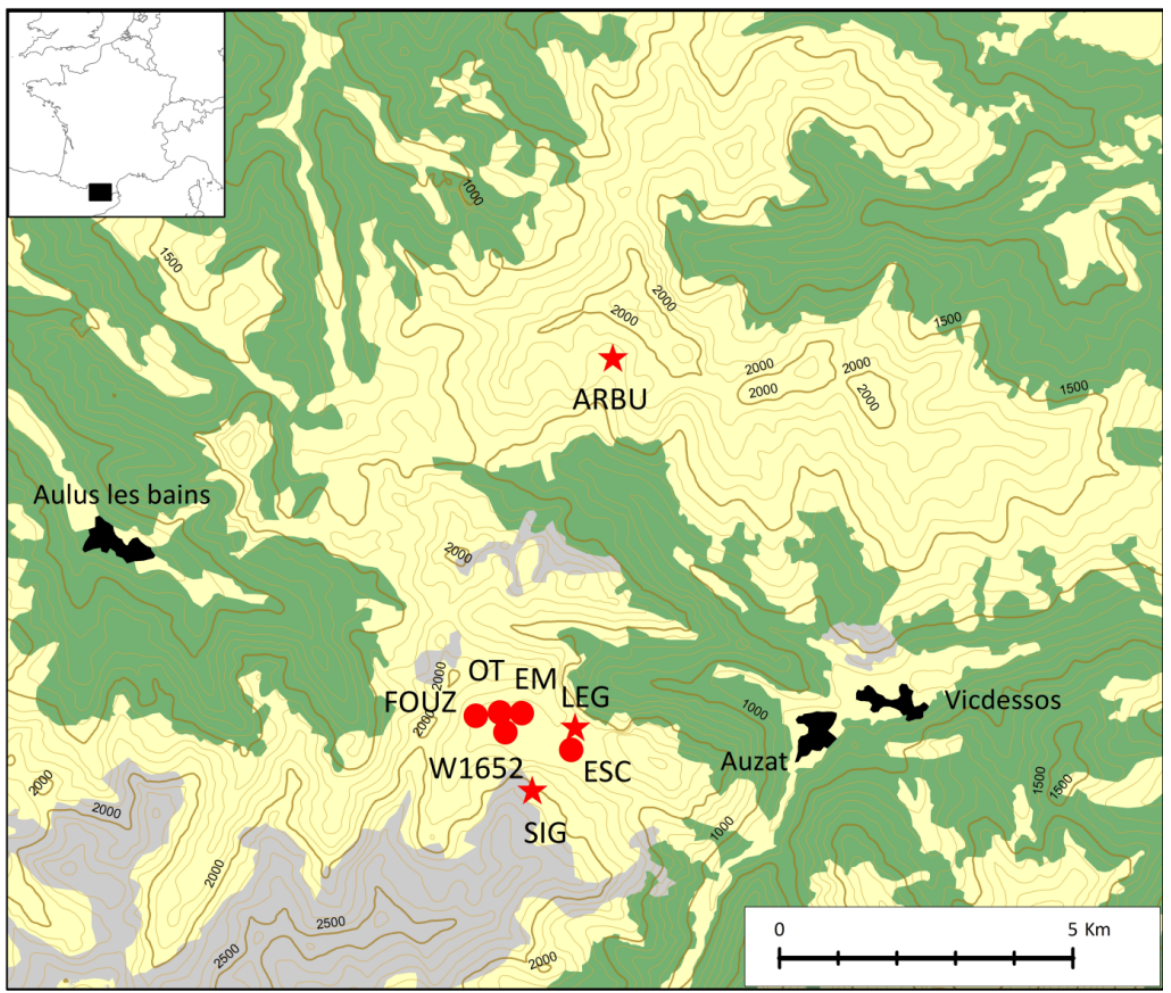

241 Figure 2 Location of the study area and pollen archives in the Vicdessos area (French Pyrenees). Yellow color 242 corresponds to open land (above the tree line), green to forests and grey to mineral surfaces. Isolines of $100 \mathrm{~m}$ are shown. 243 Seven pollen records (SIG, ESC, LEG, W1652, FOUZ, OT and EM) are located on the plateau of Bassiès and one (ARBU) $2446 \mathrm{~km}$ north of Bassiès (see Table 1 for the labels of the sites). Red dots are bogs and red stars are lakes. 
247 are given in Appendix B. Age-depth models of sediments are constructed by using both ${ }^{210} \mathrm{~Pb} \mathrm{CRS}$

248 (Constant Rate of Supply) model (Appleby, 2002) and CLAM radiocarbon age depth model (Blaauw,

249 2010). In order to build a robust age-depth model at each site, uncertainties of the ${ }^{210} \mathrm{~Pb}$ ages

250 calculated using Matlab with Monte Carlo simulations according to Binford (1990) are combined

251 with the radiocarbon uncertainties in CLAM. The pollen counts are pooled together for each 10-year

252 time window between 1960 and 2013; the most recent time window is 2000-2013. For this study we

253 select three time windows to assess the accuracy of the LRA-based reconstruction of vegetation:

254 1960-1970, 1990-2000 and 2000-2013; those are the time windows for which both the regional and

255 local land-cover maps are available. Total sum of pollen counts used for data analysis varies from

256463 (SIG) to 2164 (FOUZ), 544 (EM) to 2530 (W1652), and 1143 (ARBU) to 5812 (OT) for the

257 periods 1960-1970, 1990-2000 and 2000-2013, respectively.

\subsection{Observed land-cover maps}

For evaluation of the LRA estimates, this study obtains the regional- and local/landscape- 
266 for 1990 and 2006 are selected as a source of the observed regional land-cover for time windows of 267 1990-2000 and 2000-2013 (Fig. 3). The digitized vegetation map of Foix (oeuvre collective CNRS, 26877 Foix, 1964, Henry Gaussen) in 1964 is used for the time window 1960-1970 (Fig. 3). Note that 269 this 1964 vegetation map does not cover the entire area in the 50-km radius. For this study the land270 cover maps from three time windows $(1964,1990$ and 2006) are harmonized to be comparable to 271 each other. The regional land-cover in 2006 is characterized by broadleaved forest (27\%) and conifer

273 forest (16\%) and grasslands (24\%); arable and agricultural lands (12\%) are mainly located in the 274 northernmost corner (Fig. 3). Oak and beech are the main components of the broadleaved forests, 275 associated with birch, hazel, lime-tree, willow and ash. Pine and fir characterize the conifer forests.

276 Forested areas have increased in the 1964-2013 period. 


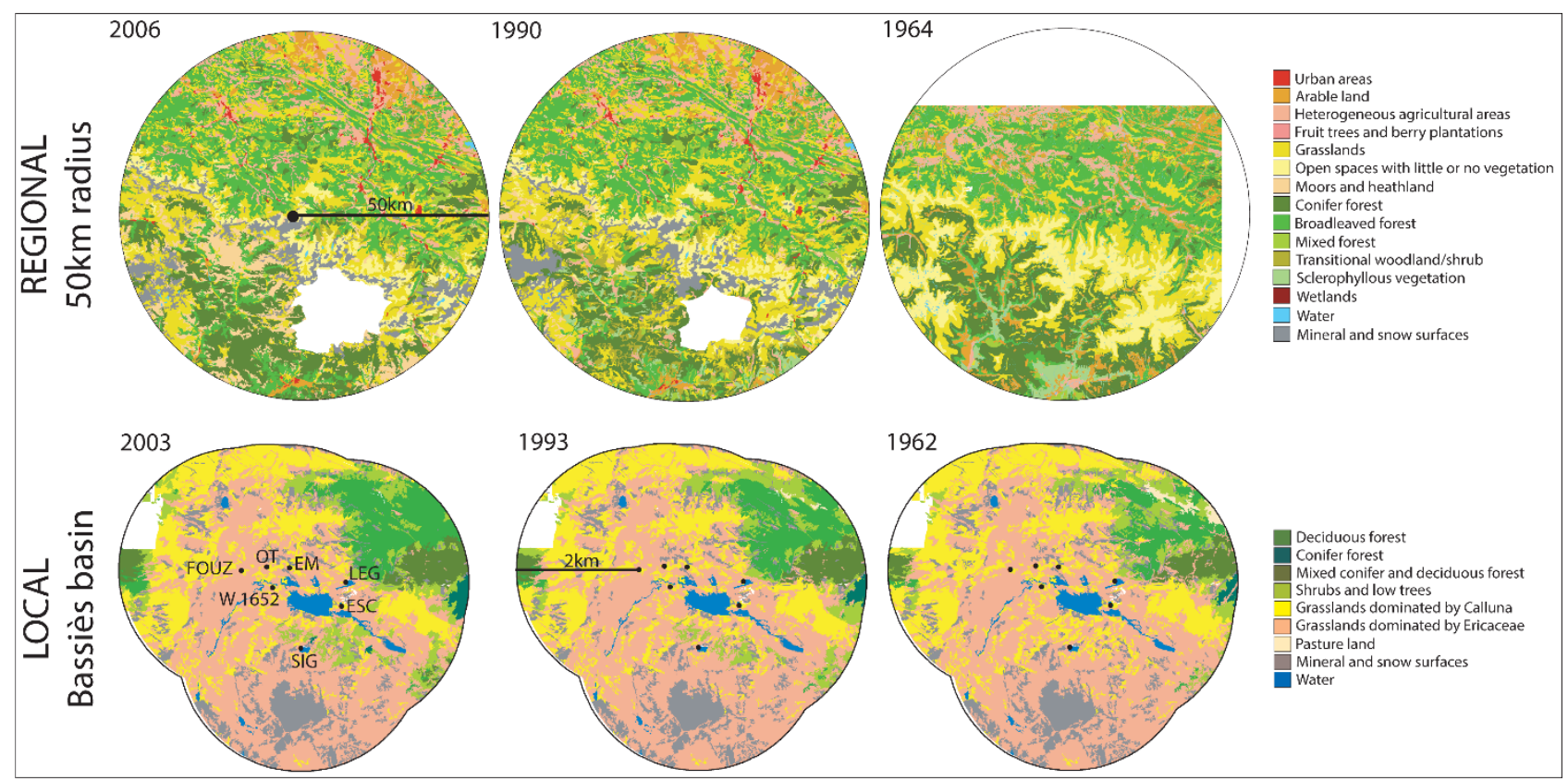

Figure 3 Observed regional land-cover maps of a 50-km radius from the plateaus of Bassiès and local land-cover maps of an agglomerated 2-km radius around each lakes and bogs (pollen archives). Regional maps are based on CORINE datasets for 2006 and 1990 and from the CNRS vegetation map "Foix 1964" for 1964. Local maps are based on series of aerial imageries (Houet et al., 2012). The meanings of the labels of each pollen record are given in Table 1. Note that white color corresponds to the absence of data.

\subsubsection{Observed local land-cover}

interest: 1960-1970, 1990-2000 and 2000-2013. These maps are based on a semi-automatic

(Houet et al., 2012).

The plateaus of Bassiès is covered by heather and rhododendron heathlands and grasslands.

Small clumps of short conifer trees are spread out over the plateaus unevenly. Forested areas are 
293 located on the neighboring slopes; conifer trees are mostly pine and fir, and broadleaved trees mostly

294 beech, birch and hazel. and land-cover maps in the study region, are selected for data analysis. Plant composition in each land-cover type is approximated according to a local botanical expert (N. de Munnik, personal

Table 2 Taxa and groups of taxa used in this study. Relative pollen productivity estimates (RPPs) of individual taxa and their standard errors, and fall speed of pollen are listed. RPP values are relative to that of Gramineae. Botanical nomenclature follows Flora Europaea (Tutin et al., 1964-1980). 


\begin{tabular}{llll}
\hline Pollen taxa & $\begin{array}{l}\text { RPP and } \\
\text { standard errors }\end{array}$ & $\begin{array}{l}\text { Fall speeds of } \\
\text { pollen }(\mathrm{m} / \mathrm{s})\end{array}$ & Groups of taxa \\
\hline Abies & $6.88+/-1.44$ & 0.12 & \\
Juniperus & $2.07+/-0.04$ & 0.016 & Conifer trees \\
Picea & $2.62+/-0.12$ & 0.056 & \\
Pinus & $6.38+/-0.45$ & 0.031 & \\
\hline Betula & $3.09+/-0.27$ & 0.024 & \\
Corylus & $1.99+/-0.19$ & 0.025 & \\
Fagus & $2.35+/-0.11$ & 0.057 & \\
Fraxinus & $1.03+/-0.11$ & 0.022 & \\
Quercus & $5.83+/-0.15$ & 0.035 & \\
Salix & $1.22+/-0.11$ & 0.022 & \\
Tilia & $0.8+/-0.03$ & 0.032 & \\
\hline Calluna vulgaris & $0.82+/-0.02$ & 0.038 & \\
Cerealia-t & $1.85+/-0.38$ & 0.06 & \\
Cichorioideae & $0.16+/-0.02$ & 0.051 & \\
Cyperaceae & $0.87+/-0.06$ & 0.035 & \\
Ericaceae & $0.07+/-0.04$ & 0.038 & \\
Gramineae & $1+/-0$ & 0.035 & \\
Plantago lanceolata & $1.04+/-0.09$ & 0.029 & \\
Plantago media & $1.27+/-0.18$ & 0.024 & \\
Potentilla-t & $1.19+/-0.13$ & 0.018 & \\
\hline & & & \\
& &
\end{tabular}

\section{$314 \quad 3.3$ Evaluation of the LRA-based vegetation reconstruction}

$315 \quad$ 3.3.1 Testing strategy

This study uses pollen records from eight sites for the LRA-based vegetation reconstruction

317 in the regional- and local/landscape-scales. Three categories of land-cover types are considered for

318 evaluation: areas covered by conifers, broadleaved trees, and open land characterized by Ericaceous

319 shrubs, graminoids and other herbaceous plants. The results - both the REVEALS-based estimates of

regional vegetation and the LRA-based estimates of local vegetation - are evaluated against the 

composition of those three categories of land cover regionally and locally. Both the GPM and LSM options are applied in the LRA as the pollen dispersal functions (as in section 2). Figure 4 summarizes the testing scheme described in this section, and Table 3 the nomenclature for the models, data sets used, and model outcomes. Since pollen data are available only from small-sized sites $<4$ ha (Table 1 ), we use a leaveone out strategy (LOO; Efron and Tibshirani, 1998; Sugita et al., 2010; Mazier et al., 2015) to avoid circularity in the LRA process: that is, selection of one site for local vegetation reconstruction with LOVE and the other seven sites for regional vegetation reconstruction with REVEALS. This process is repeated for all the eight sites in the study area. Theoretically and empirically the REVEALS results prove to be robust even when pollen data from several small-sized lakes and bogs are used (Sugita, 2007a; Sugita et al., 2010; Fyfe et al., 2013; Trondman et al., 2016; Hjelle et al. 2018; and others), although error estimates would be large. Hereafter, the REVEALS-based estimates of regional vegetation is referred to as RVs_LOO. Another set of estimates for the regional vegetation composition within a 50-km radius from individual sites is compiled from the land-cover maps (section 3.2) and used as inputs for the LOVE application, independently and separately from RVs_LOO; hereafter, the data set is referred to as RVs_MAP50. Both RVs_LOO and RVs_MAP50 are then applied for reconstruction of the 
339 the LOVE model for comparison. The inverse modeling of LOVE (Sugita, 2007b; Sugita et al., 2010)

340 is applied for estimating the RSAP with RVs_MAP50 around the plateaus of Bassiès in the three time

341 windows.

In addition, RVs_MAP50 is compared to the REVEALS results using pollen records from all

343 the eight sites together, referred to as RVs, to evaluate the extent to which the pollen-based

344 reconstruction reflects the observed vegetation composition of the region for the sake of simplicity.

345 The differences between RVs and individual RVs_LOO are negligible.

The LOVE results with either RVs_LOO or RVs_Map50 are evaluated against the plant

347 composition data extracted from the observed local land-cover maps in each time window. The

348 proportions of the areas $\left(\mathrm{m}^{2}\right)$ occupied by each land-cover type are estimated in successive concentric

349 rings at $20-\mathrm{m}$ increment out to $2 \mathrm{~km}$ from the center of each site. Cumulative estimates of plant

350 composition within a 2-km radius are calculated, using a distance weighting method (either with the

351 LSM or GPM option) and fall speed of pollen for the 20 taxa as listed in Table 2. For all the

352 calculations this study uses ArcGIS 10.2.2, a script in $\mathrm{R}$ (Binet, unpublished) and

353 "DWPAcalculator.v7.3a" (Sugita, unpublished). 


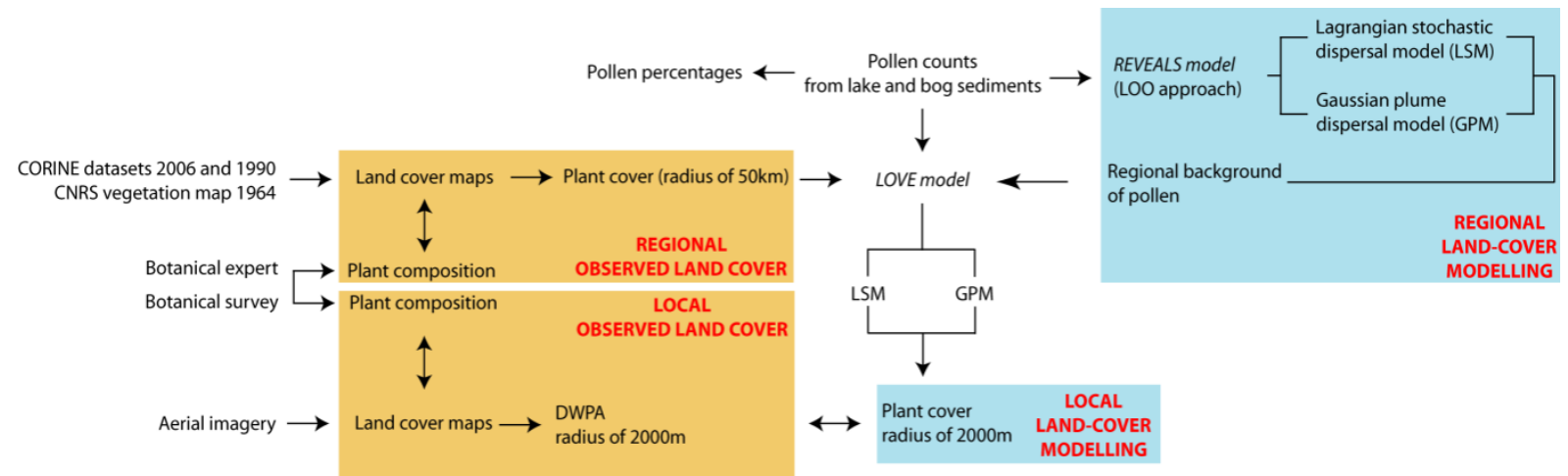

359 Figure 4 Flow chart of the methodological approach. LOO: Leave One Out approach. DWPA: Distance weighted plant 360 abundance.

\begin{tabular}{ll} 
Model data/name & Meaning \\
\hline LRA & Landscape Reconstruction Algorithm: REVEALS + LOVE models \\
REVEALS & Model for regional land-cover reconstruction \\
LOVE & Model for local land-cover reconstruction \\
POLLSCAPE & Model for landscape simulation \\
DWPA & Distance Weighted Plant Abundance \\
RSAP & Relevant Source Area of Pollen \\
RPP & Relative Pollen Productivity estimates \\
GPM & Gaussian Plume Model as pollen dispersal model \\
LSM & Lagrangian Stochastic Model as pollen dispersal model \\
RVs & The eight pollen archives are used with REVEALS \\
RVs-LOO & $\begin{array}{l}\text { Seven pollen archives are used with REVEALS; LOO: Leave One Out } \\
\text { approach } \\
\text { Regional land-cover reconstruction based on the CORINE map } \\
\text { RVs-MAP50 }\end{array}$ \\
SE & $\begin{array}{l}\text { Standard errors } \\
\text { Local vegetation estimates for a RSAP of 2-km radius with RVs-LOO as } \\
\text { regional background of pollen }\end{array}$ \\
LRA-LOO & $\begin{array}{l}\text { Local vegetation estimates for a RSAP of 2-km radius with RVs-MAP50 as } \\
\text { regional background of pollen }\end{array}$ \\
LRA-MAP50 & \\
\hline
\end{tabular}


We use the pollen count data from three lakes and five bogs as inputs to the LRA. Our

preliminary trials (not shown) show that the selection of basin type (i.e. lake or bog) does not affect

the outcomes significantly; accordingly all the REVEALS and LOVE applications assume that the

pollen data used are from bogs. For model calculations this study uses a set of RPPs and fall speed of

pollen from Mazier et al. (2012) (Table 2) that is used in the LANDCLIM project (Trondman et al.,

2015; Marquer et al., 2014, 2017) and other projects in Europe.

estimates. We therefore apply a threshold of $1 \%$ to select the major pollen taxa recorded in both the

pollen and observed vegetation data sets. Accordingly, eighteen taxa are selected. Two additional

taxa (fir and juniper), locally important for the vegetation history of the Vicdessos valley, are added;

We use "LRA.REVEALS.v6.2.2.exe" and "LRA.LOVE.v6.2.3.exe” for data analysis (Sugita,

unpublished). When the GPM option is used, pollen dispersal in a neutral atmospheric condition is

assumed with wind speed of $3 \mathrm{msec}^{-1}$ (although the local wind speed varies mostly between 0 and 4

msec $^{-1}$ (Szczypta et al., 2015; Claustres, 2016)). $Z_{\max }$, the maximum spatial extent of the regional 
the LSM option is applied, $\mathrm{Z}_{\max }$ is automatically set to $100 \mathrm{~km}$; all other conditions and parameters

386

specific to the model are the same as those in Kuparinen et al. (2007) and Theuerkauf et al. (2016).

The REVEALS and LOVE results are expressed in proportion cover for three land-cover types: conifers, broadleaved trees, and open-land taxa (Table 2); their standard errors are obtained according to the delta method (Stuart and Ord, 1994).

The regional plant composition based on the CORINE maps - RVs_MAP50 - do not have error estimates (SEs), and these estimates are needed as inputs for the LOVE runs. We therefore have calculated SEs for RVs_MAP50 by taking into account both SEs that were previously obtained from RVs and both GPM and LSM options as follow:

$$
S E_{i}=\frac{\frac{S E_{R V_{G P M}} i}{R V_{G P M} i}+\frac{S E_{R V_{L S M}} i}{R V_{L S M} i}}{2} \times R V_{M A P 50} i
$$

where $S E_{R V_{G P M}} i$ and $S E_{R V_{L S M}} i$ are the standard errors for species i of RVs using the GPM (RV $V_{G P M} i$ ) and $\operatorname{LSM}\left(R V_{L S M} i\right)$ option, respectively. $R V_{M A P 50} i$ is RVs_MAP50 for the species $i$.

\section{RESULTS}

\subsection{Estimates of the regional vegetation composition}

When the forested (i.e. conifers and broadleaved trees together) and unforested (i.e. open land) covers are concerned, the REVEALS results (RVs) are largely overestimating open land, in particular 
the ones using the LSM, in comparison to the observed data (RVs_MAP50); on the other hand,

403 forested areas are overestimated by pollen proportions alone (the left graph in Figure 5). In general,

404

405

406

407

408

409

410

411

RVs (with pollen data from all sites) using REVEALS with either the GPM or the LSM are more dissimilar to the CORINE-map based estimates (RVs_MAP50) than pollen proportions alone.

The right graph of Figure 5 depicts the results along three axes of land cover types: open land, conifers and broadleaved trees. Conifers and broadleaved trees are overestimated in pollen proportions in comparison to RVs_MAP 50. Open land cover is overestimated in RVs relative to RVs_MAP50.RVs with the GPM tend to be more similar to RVs_MAP50 than RVs with the LSM.

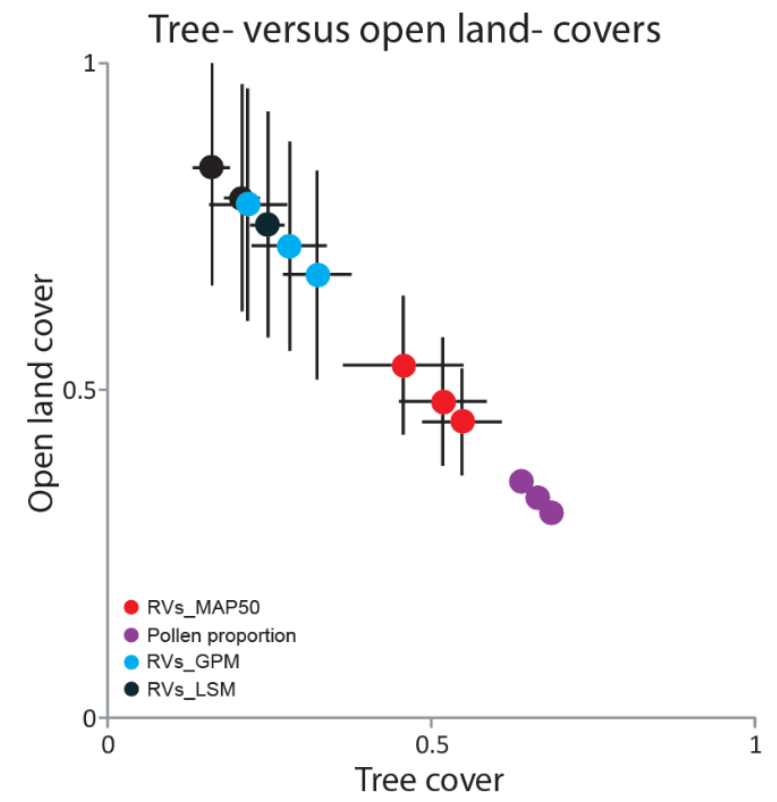

Groups of taxa

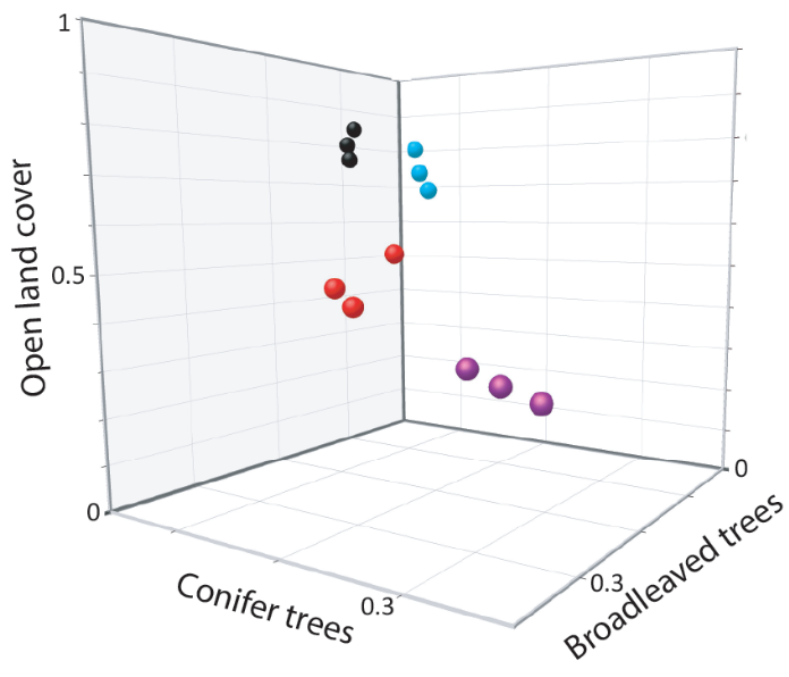

Figure 5 Differences between RVs_MAP50 (i.e. observed regional land-covers for 2006, 1990 and 1964), pollen proportions (untransformed pollen data) and REVEALS (RVs) using all local pollen records together for the three time windows, 2013-2000, 2000-1990 and 1970-1960. REVEALS estimates have been calculated using both pollen dispersal model alternatives, GPM and LSM. Results are shown for tree- versus open land- cover and groups of taxa (conifer trees, broadleaved trees and open land taxa). The error bars are shown for the tree-versus open land-covers. 
in general. Standard errors for pollen proportions, which represent the counting errors of pollen grains

419 are too low to be plot in Figure 5.

\subsection{Relevant source area of pollen (RSAP)}

option and from 1933 to $5113 \mathrm{~m}$ with the LSM option (Table 4); the former is consistently lower than

424 the latter in each time window. In four cases out of six, the RSAP estimates is lower than $2 \mathrm{~km}$; the

429 discussion section.

431 Table 4 The relevant source areas of pollen (RSAP) based on LOVE runs using RVs_MAP50 as regional vegetation

\begin{tabular}{cccc} 
& RVs_MAP50_2006 & RVs_MAP50_1990 & RVs_MAP50_1964 \\
\hline RSAP - GPM & $1038 \mathrm{~m}$ & $888 \mathrm{~m}$ & $663 \mathrm{~m}$ \\
RSAP - LSM & $4693 \mathrm{~m}$ & $1933 \mathrm{~m}$ & $5113 \mathrm{~m}$ \\
\hline
\end{tabular}




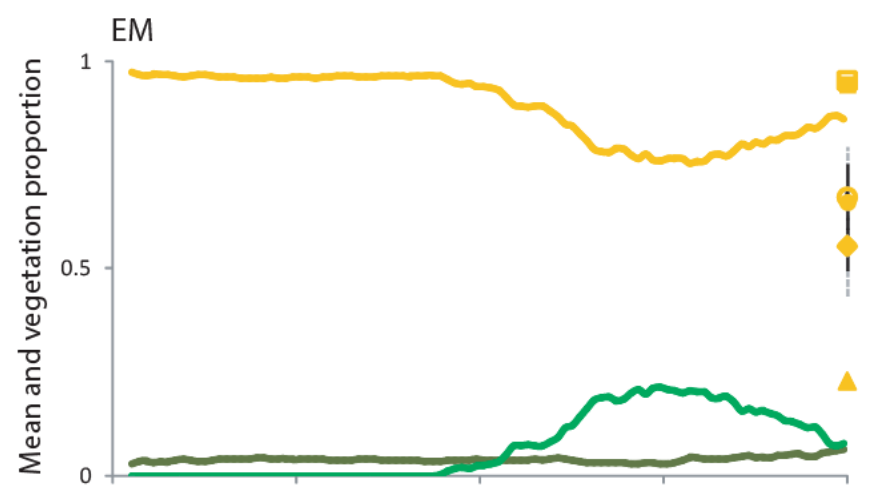

ESC

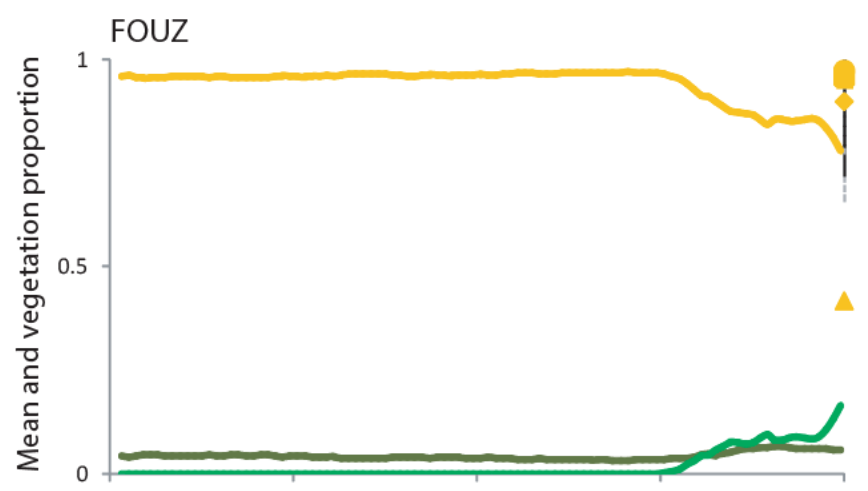

LEG

OT

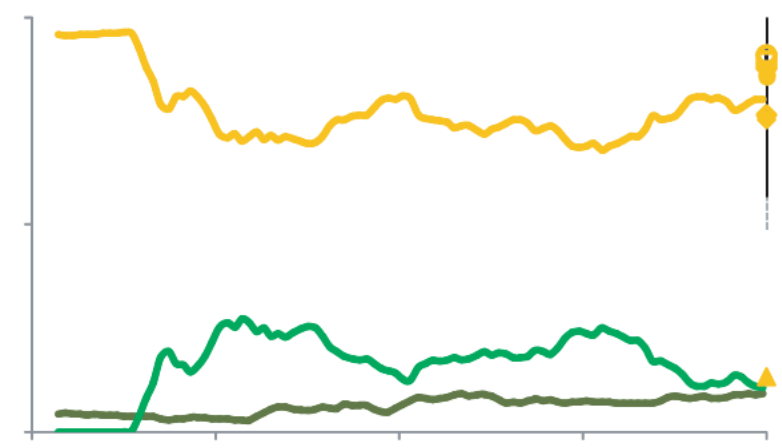

SIG

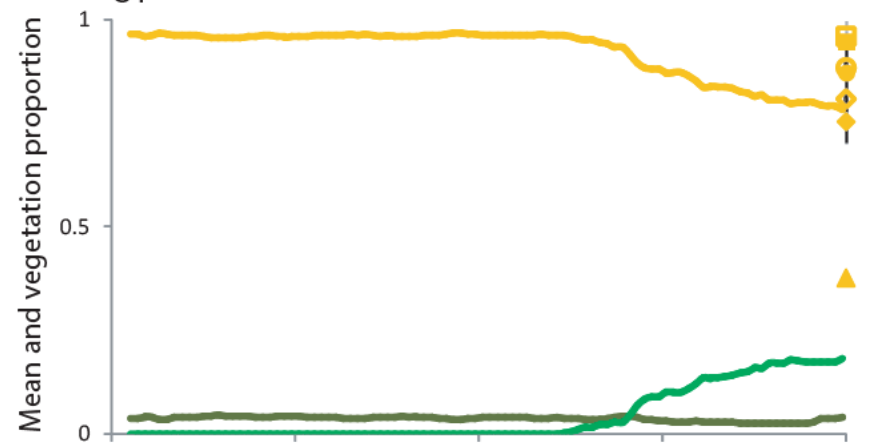

W1652
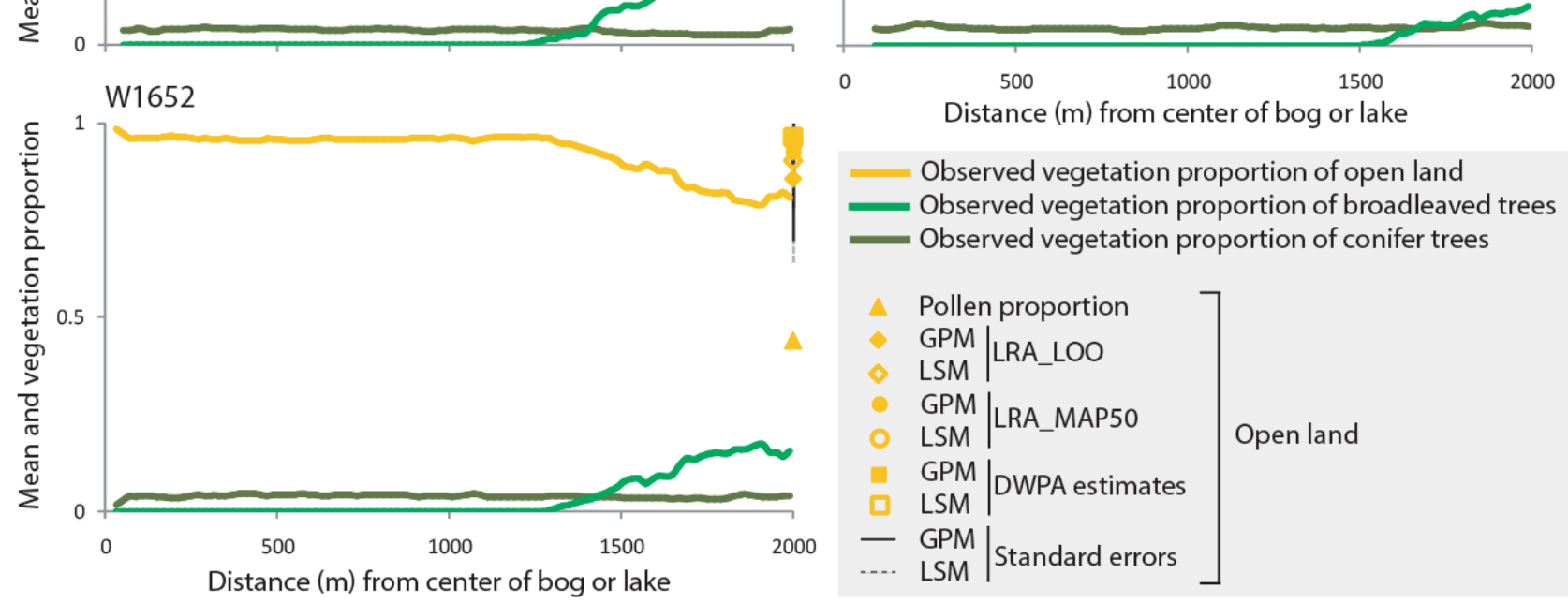

Figure 6 Spatial distribution of observed vegetation proportion based on local maps at a scale of incremental 20-m rings from the center of each site. Results are shown for the three groups of taxa, i.e. open land, broadleaved and conifer trees.

437 Mean pollen proportion (untransformed pollen data) and LRA and DWPA estimates are given at a distance $2 \mathrm{~km}$ for each 438 site. Note that pollen proportion, LRA and DWPA estimates are means over the whole $2 \mathrm{~km}$. Results from all alternative scenarios we have used in this study are shown as well as the standard errors, for open land category. All data presented in this figure correspond to the time window 2013-2000. See Table 1 and Figure 2 for labels and site locations. 


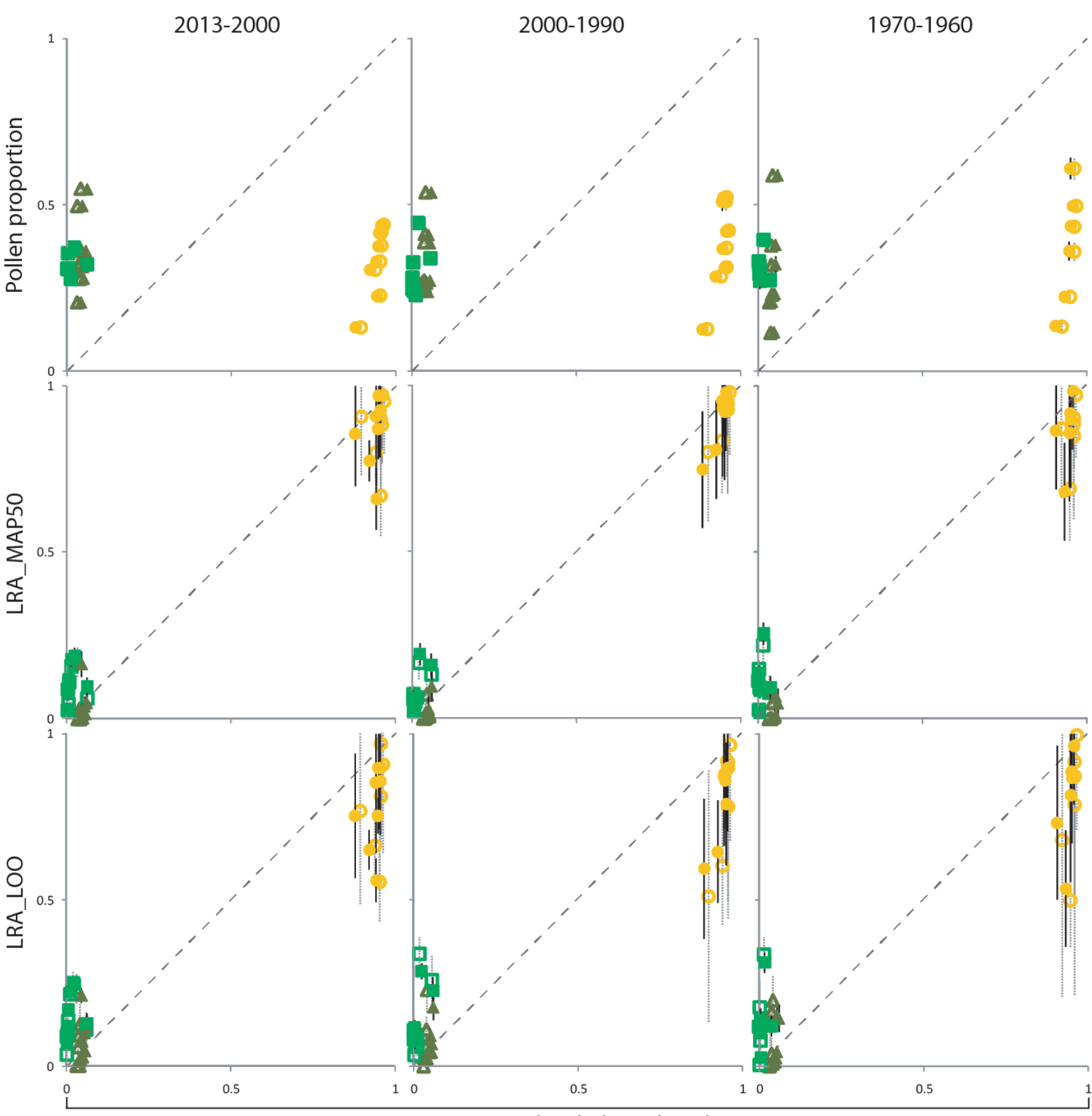

Distance weighted plant abundance

Figure 7 Comparison distance weighted plant abundance based on observed local land-cover maps against pollen proportion (untransformed pollen data) and two sets of LRA estimates, LRA_MAP50 and LRA-LOO (see text for further explanation). The results are shown for the three studied time windows. Each point represents a site. Pollen proportions and LRA estimates are reasonable representation of observed local land-cover (expressed here as distance weighted plant abundance) when pollen records are close to the dashed line. 


\subsection{Evaluation of the LRA-based reconstruction of vegetation within a 2-km radius}

451

452

453

454

455

456

457

458

459

460

461

462

463

\subsubsection{Relationship between the spatial structure of plant composition and the LRA results}

Figure 6 summarizes the spatial distribution of the three land-cover types in proportion from the basin shore out to $2 \mathrm{~km}$ at each site in the 2000-2013 window. Additional information is plotted at the right end of each graph at each site, including (1) pollen proportion of plant types that indicate open land, (2) the LRA-based estimates of open-land cover within a 2-km radius, with various calculation settings tested (in a distance-weighted fashion; Sugita, 2007b), and (3) the cumulated

DWPA at $2 \mathrm{~km}$ from the center of each site (expressed in proportion) calculated from the local landcover maps. The LOVE model reconstructs the local vegetation in proportion based on the cumulative DWPA within the RSAP (Sugita, 2007b) as a whole; thus, it is theoretically hard to look into the spatial structure of local vegetation within the RSAP in detail. Figure 6 assists to visualize better the extent to which the spatial structure of the local land cover would influence the LRA results in the study area. Note that ARBU belongs to another watershed and detailed maps of the local land cover are unavailable; therefore we do not include the site information in the figure.

Open land characterizes the immediately surrounding areas around individual sites. The distances, at and beyond which tree covers (mostly broadleaved trees) increase, vary site to site: 270 , 650, 900, 1250, 1300, 1500 and $1600 \mathrm{~m}$ at LEG, ESC, EM, OT, W1652, FOUZ and SIG, respectively. The broadleaved-tree cover rises up to $10,16,17,18,21,22$ and $25 \%$ within a $2-\mathrm{km}$ radius at SIG, 
FOUZ, W1652, OT, EM, ESC and LEG, respectively.

Except for the EM site, the LRA-based reconstruction of open land is mostly in good

agreement with the estimates based on the cumulated DWPAs at $2 \mathrm{~km}$ from each site. LRA_LOO for

471

open land varies between 65 and 97\% and LRA_MAP50 between 77.5 and 97\% among the sites,

472

whereas the open-land proportion based on the cumulative DWPA ranges from 88 to $96 \%$; all those

473

results consider the vegetation cover within a $2-\mathrm{km}$ radius as a whole. At those seven sites the open-

474

land cover from the shore out to $2 \mathrm{~km}$ changes from 68 to $98.5 \%$. The EM site is an exception. The

LRA-based results of open land at EM are underestimated, relative to the estimate based on the

cumulative DWPA; both LRA_LOO and LRA_MAP50 vary between 55 and 67\%, but the cumulative

DWPA-based estimates range from 94 to $95 \%$. The range of the changes in open land from the shore out to $2 \mathrm{~km}$ is from 75 to $97 \%$ at EM.

sites, and thus significantly underestimate both the cumulative DWPA-based estimates and the

observed proportions of the open-land cover within a 2-km radius (Figure 6). Three graphs in the top

row of Figure 7 also demonstrate clearly that pollen proportions alone do not correspond to the

DWPA-based estimates of all the three land-cover types within a 2-km radius in all time windows.

Although expected, those results reaffirm that the LRA-based results are more realistic than pollen 
Against the cumulative DWPA-based estimates of vegetation cover within a 2-km radius,

LRA_MAP50 is a better choice for all the land-cover types than LRA_LOO in the three time windows

(Figure 7). Relative to the LRA_LOO results (the bottom row of Figure 7), the LRA_MAP50

estimates tend to have smaller standard errors at individual sites, to have smaller site-to-site variations the LRA estimates for each land-cover type. 
LRA_LOO for open land vary from $10.5-57 \%$; on the other hand, those vary from 5.2 to $26.1 \%$ with the GPM option. When LRA_MAP50 is concerned, the differences influenced by the selection of the dispersal model are negligible: the SEs vary from 7.4 to $25.2 \%$ with the LSM option and from 5.2 to $26.1 \%$ with the GPM option. As suggested in the simulations in section 2, the systematic selection of pollen sites in mountains, which is the case for RVs_LOO (and thus affecting LRA_LOO), is a suspect for those results on the differences in the SEs.

\section{DISCUSSION} too simple for landscapes with complex topography and wind field in mountain regions. However,

517 the simulations (section 2) and the application results in the Vicdessos area show that some of the 518 difficult issues associated with pollen-based reconstruction of vegetation in mountains can be 519 addressed and overcome. 
Pollen-based reconstruction of mountain vegetation often selects small-sized pollen sites only in mountains and high-altitude plateaus. This site-selection strategy is useful for evaluating sitespecific correlational relationships between pollen assemblages and the surround vegetation; however,

526 it makes the LRA-based quantitative reconstruction of vegetation difficult. The REVEALS-based estimates of regional vegetation - an important outcome from the first step of the LRA- are critical for evaluating the abundance of long-distance pollen from the regional sources that are assumed to be consistent among small-sized sites for the LOVE applications. However, when several small-sized sites are selected above the tree line on the same land cover type, we expect biased estimates of the regional vegetation within a $50-100 \mathrm{~km}$ radius. This is the case in our study in the Vicdessos area

532 (Figure 5); the regional components of the open land cover are overestimated by REVEALS. Because 533 pollen records from small-sized sites tend to represent local vegetation (Prentice, 1985; Sugita, 1994), 534 we expect that the REVEALS results based on pollen records from those sites underestimate the 535 abundances of tree covers in the region. regional reliable pollen archives; Sugita, 2007a; Trondman et al., 2016) and/or several small sites

538 (lakes and bogs) located in various valleys, slopes and altitudes in the region, although reliable pollen 539 sites in mountains are mainly small and located in sub-alpine or alpine zones (Simonneau et al., 2013). 
540 Abraham et al. (2017) used pollen records from small sites located above and below the treeline in

541 low mountain ranges of NE Czech Republic and obtained reasonable REVEALS estimates of past

542 regional vegetation. Hjelle et al. (2015) have used pollen samples from one large lake and twenty-

543 eight small lakes located in different types of vegetation in western Norway. They found a good

544 relationship between the REVEALS estimates and CORINE land-cover data, although the

545 REVEALS model tends to overestimate open land cover against the CORINE land-cover. Hjelle et

546 al. further show that the higher the number of small lakes, the more reliable the REVEALS estimates.

547 Thus, establishing a proper site-selection scheme is the important step for REVEALS applications,

548 although it is hard to find a large number of suitable pollen sites in mountain regions.

As expected, the LRA results using RVs_MAP50 are better matched with the map-based DWPAs within a 2-km radius than those using RVs_LOO (Figure 7). Standard errors of LRA_MAP50s are smaller than those of LRA_LOOs, in general. Those results demonstrate the

552 importance of the accuracy and reliability of the regional estimates of vegetation and land cover for

553 the LRA approach. Even so, it's also encouraging that the RVs_LOOs are usable to provide robust 554 estimates of LRA_LOOs using our data set. 
560 simulations and the empirical study at the Vicdessos area (Figure 7). A LSM scheme is more

561 advanced and realistic in description of atmospheric airflow and long-distance particle dispersal than

562 a GPM scheme (Kuparinen et al., 2007). Comparisons between REVEALS_LSM and

563 REVEALS_GPM (Theuerkauf et al., 2013, 2016) using pollen records from lakes in NE Germany

564 showed the superiority of the use of the LSM of Kuparinen et al. (2007) over the GPM traditionally

565 used in pollen-based vegetation modelling. Mariani et al. (2017) came to the same conclusion based

566 on their study in Tasmania. We expected that applications of the LSM would improve the LRA results,

567 in particular reducing biases on the long-distance pollen from the regional source, caused by complex

568 topography and wind field in mountains. However, our results show that the REVEALS_GPM-based

569 estimates of the regional vegetation cover tend to be closer to the observed regional land-cover than

570 those by REVEALS_LSM (Figure 5); the LSM and GPM options do not influence significantly the

571 LOVE results.

The LSM takes into account higher updraft velocities in air via turbulence better than the

573 GPM (Kuparinen et al., 2007); thus, heavier pollen types, such as Abies and Fagus, tend to be

574 modeled to disperse further with the LSM than with the GPM (Sutton, 1953). The consequence is 
types with high fall speed of pollen, than the LSM does (Kuparinen et al., 2007; Theuerkauf et al.,

577 2013), and in our study this is the cause of the underestimation of Abies and Fagus based on LSM,

578 and thereby of the overestimation of regional open land based on LSM.

Size of pollen-sampling sites may be one of the possible reasons why the LRA estimates with

the LSM option do not improve significantly against those with the GPM option. Indeed, the LSM

would be a better option for pollen dispersion and deposition in large lakes than the GPM; pollen however, as the simulations (section 2) demonstrate. Another important issue is the availability of the estimates of relative pollen productivity, RPP,

591 for the constituent taxa used for data analysis. This study uses RPPs that were compiled from previous 
594 Ideally, when the LSM is used for the LRA, RPPs need to be obtained from other data sets by

595 assuming the LSM as a pollen dispersal model for consistency. Theuerkauf et al. $(2013,2016)$

596 obtained RPPs of selected taxa in lowlands in North Germany; however, Asteraceae and Ericaceae,

597 important taxa in our study, are not included. Mariani et al. $(2016,2017)$ estimated RPPs for selected

598 taxa in Tasmania. Thus far, the LSM-based estimates of RPPs are available from one study only in

599 NE Germany; considering their variations caused by various environmental and anthropogenic

600 factors, it is necessary to expand the database of the LSM-based RPPs for further applications of the

601 LSM in the LRA reconstruction. All things considered, it is justified for this study to use RPPs for

602 the selected taxa from NW Europe (Mazier et al., 2012; Trondman et al., 2015; Marquer et al., 2014, 603 2017).

604

\subsection{The LRA-based reconstruction of vegetation composition with insect-pollinated plants}

Plant communities at the mountain tops in our study region are characterized by high

607 abundance of insect-pollinated taxa such as Ericaceae (e.g. Rhododendron spp. and Vaccinium spp.)

608 with semi-dominant grass and Calluna (heather). Ericaceae plants have low pollen production (see

609 Table 2) relative to the wind-pollinated taxa in general (Mazier et al., 2012); then fall speed of pollen

610 being similar among the constituent taxa, the LRA estimates of Ericaceae, thus the open land cover,

611 tend to increase relative to the other taxa and land cover types. Mazier et al. (2012) excluded 
zoophilous taxa from the REVEALS reconstruction, mainly because the model assumes that all pollen

grains are coming via wind transport. However, the majority of the upland plant taxa common on

mountain tops are zoophilous. It is ecologically important to include zoophilous taxa in pollen-based

reconstruction of vegetation. Mariani et al. (2017) used both wind- and animal-pollinating plant taxa

together for the REVEALS applications in Tasmania successfully. In the Pyrenees, this study also

demonstrates that the LRA approach appears working reasonably well with zoophilous taxa for

\subsection{Relevant source area of pollen (RSAP) and LRA estimates of local vegetation in mountains}

plant abundance at the RSAP (e.g., in biomass, plant cover, foliage mass, basal area, etc.) that is 
pollen-vegetation relationship, the site-specific spatial structure of vegetation within the RSAP is

631 impossible to assess quantitatively. Figure 6 is an attempt to visualize how different the spatial

632 structure of the surrounding vegetation at individual sites could be, even when the LRA results are

633 relatively similar among most of the sites.

634

The RSAP estimates (Table 3), which are obtained with an inverse modeling of LOVE (Sugita,

635 2007b; Sugita et al., 2010), are significantly smaller with the GPM option than those with the LSM

636 option at all time windows. This is contradictory to the simulation results in section 2; the LRA-based

637 estimate of the RSAP with the GPM option (i.e. $310 \mathrm{~m}$ ) is only slightly smaller than that with the

638 LSM option (i.e. $325 \mathrm{~m}$ ). The GPM describes pollen dispersal in such a way that pollen grains,

639 especially heavy pollen types such as Ericaceae fall to the ground in shorter distances than the LSM

640 does (Kuparinen et al., 2007; Theuerkauf et al., 2016; see also section 5.2). On the other hand, the

641 LSM predicts higher abundance of long-distance pollen from the regional source, including arboreal

642 plants growing abundantly in lower altitudes, into mountain sites than the GPM does. All these factors,

643 as well as others (e.g., the spatial structure of mountain vegetation, non-random selection of pollen-

644 site location, and the lack of RPP estimates considering LSM) would interact and affect the LRA-

645 based estimates of the RSAP in unknown ways. Further studies are necessary.

Among the six RSAP estimates listed in Table 3, four estimates are close to or smaller than 2 
648 studies also show that the RSAP estimates are smaller than $2.8 \mathrm{~km}$ in radius, when pollen sites are

649 small- to medium-sized (Sugita et al., 2010; Overballe-Petersen et al., 2013; Cui et al., 2013, 2014;

650 Poska et al., 2014; Hjelle et al., 2015; Mazier et al., 2015; Abraham et al., 2017). In practice, the local

651 vegetation maps are available only within a 2-km radius around each site for comparison, as well. All

652 things considered, the area within a 2-km radius is appropriate to be used as the RSAP for the study,

653 with which all the results in Figures 6 and 7 are obtained.

654

Figure 6 shows that the areas close to the sampling sites are mostly unforested; tree cover

655 (mostly broadleaved trees) increases at and beyond 270-1600 m depending on the sites. The DWPA

656 results depict that, with either the GPM or LSM option, the open-land cover is dominant consistently.

657 Except for the EM site, the LRA_LOOs and LRA_MAP50s within a 2-km radius are reasonable

658 against the DWPAs; these results assure the relevance of the LRA approach in this area. At the same

659 time it is clear that the spatial structure of vegetation within the RSAP varies among sites significantly,

660 even though the site-to-site variation of the LRA results is small. It's hard to speculate the site-specific

661 spatial structure of vegetation within the RSAP based on the LRA approach or something else.

When the GPM option is selected, the radii of the LRA-based RSAP vary from $663 \mathrm{~m}$ (1960-

663 1970) to $888 \mathrm{~m}(1990-2000)$ to $1038 \mathrm{~m}$ (2000-2013), indicative of a shift in the "grain size" of the

664 spatial structure of the surrounding vegetation around the sites (Sugita, 1994; Bunting et al., 2004).

665 It is reasonable to assume that changes in climate regimes and anthropogenic forcing in the area have 
666 affected the spatial structure of vegetation and land cover constantly.

\section{CONCLUSIONS}

The main conclusions from this study are:

- The LRA approach is a significant improvement in pollen-based reconstruction of mountain vegetation in the local- and landscape-scales over pollen percentages alone.

- Both the simulations and empirical model-data comparison in the Pyrenees demonstrate that accuracy of the regional estimates of vegetation matters for reconstruction of the local/landscape scale reconstruction of mountain vegetation in the LOVE applications. influenced by selection of pollen dispersal model and the systematic selection of pollen sites on mountains. Historical land-cover maps are effective as an alternative source for the regional vegetation in the last couple of centuries. in the Vicdessos area in the Pyrenees in the three time windows evaluated.

- Insect-pollinated plant taxa, often important to characterize vegetation in higher altitudes, can be included and informative for the LRA-based vegetation reconstruction in mountains. 
- Further clarification is necessary to better understand the pros and cons of two dispersal models - the Lagrangian Stochastic Model and Gaussian Plume model - for the LRA applications in mountain environments. The present work provides an important basis for reliable palaeoecological reconstruction in the Pyrenees and for advances in research about the past and recent intense human impact in the region. Further studies will help improve some of the modelling approaches for a better understanding of the spatial and temporal distribution of plant taxa within a catchment (Plancher et al., in prep.) and the reconstruction of local paleorainfall by using the erosion processes (Allen et al., in press).

\section{ACKNOWLEGEMEMNTS}

This work is part of the TRAM (Trace metal legacy on mountains aquatic ecogeochemistry)

694 and MODE-RESPYR (Modeling Past and future land cover changes in the Pyrenees) projects

695 (supported by The French National Research Agency) coordinated respectively by G. Le Roux and

696 T. Houet, the PEPS CNRS POPEYE « Du POllen aux PalEopaYsagEs montagnard, vers un

697 développement méthodologique » project coordinated by F. Mazier and the Observatoire Hommes-

698 Milieux Pyrénées Haut Vicdessos (Labex DRIIHM) research program coordinated by D. Galop. It is also a contribution to the PAGES LandCover6k working group 
project). We thank ARTEMIS facility (CNRS-Gif sur Yvette, France) for radiocarbon dating of the

samples, and P. van Beek and M. Souhaut at the LAFARA underground laboratory where the

sediment samples have been analyzed for ${ }^{210} \mathrm{~Pb}$ and ${ }^{137} \mathrm{Cs}$ to establish chronologies.

705

\section{REFERENCES}

707 Abrahama, V., Novák, J., Houfková, P. et al. (2017) A Landscape Reconstruction Algorithm and 708 pedoanthracological data reveal Late Holocene woodland history in the lowlands of the NE Czech 709 Republic. Review of Palaeobotany and Palynology, 244, 54-64.

Appleby, P.G. (2002) Chronostratigraphic Techniques in Recent Sediments. In: Last, W.M. \& Smol, records and the De Ploey erosion model in an examination of mountain catchment erosion susceptibility and total rainfall reconstruction. Catena.

Allen, D. Simonneau, A., Le Roux, G. et al. (accepted for publication) Considering lacustrine erosion

Binford, M.W. (1990) Calculation and uncertainty analysis of $210 \mathrm{~Pb}$ dates for PIRLA project lake

Birks, H.H. \& Birks, H.J.B. (2000) Future uses of pollen analysis must include plant macrofossils. 
Blaauw, M. (2010) Methods and code for 'classical' age-modelling of radiocarbon sequences. Quaternary Geochronology, 5, 512-518.

Broström, A., Sugita, S. \& Gaillard, M.J. (2004) Pollen productivity estimates for the reconstruction of past vegetation cover in the cultural landscape of southern Sweden. The Holocene, 14, 368-381.

Broström, A., Sugita, S., Gaillard, M.J. et al. (2005) Estimating spatial scale of pollen dispersal in the cultural landscape of southern Sweden. The Holocene, 15, 252-262.

Claustres, A. (2016) Répartition des éléments traces potentiellement toxiques dans les zones de montagne : Rôle et part des facteurs naturels et anthropiques à l'échelle des temps pédologiques. Thèse de doctorat de l’Université de Toulouse III Paul Sabatier. history of the hemiboreal and southern boreal zones of southern Sweden, as revealed by the application of the Landscape Reconstruction Algorithm: implications for biodiversity and climatechange issues. The Holocene, 23, 1747-1763. 
738 David, F. (1993) Altitudinal variation in the response of the vegetation to Late-glacial climatic events 739 in the northern French Alps. New Phytologist, 125, 203-220.

740 David, F. (1997) Holocene tree limit history in the northern French Alps stomata and pollen evidence.

741 Review of Paleobotany and Palynology, 97, 227-237.

742 MacDonald, D., Crabtree, J.R., Wiesinger, G. et al. (2000) Agricultural abandonment in mountain

743 areas of Europe: Environmental consequences and policy response. Journal of Environmental 744 Management, 59, 47-69.

745 Efron, B. \& Tibshirani, R.J. (1998) An Introduction to the Bootstrap. Chapman \& Hall/CRC, Boca 746 Raton.

747 Fall, P.L. (1992) Spatial patterns of atmospheric pollen dispersal in the Colorado Rocky Mountains, $748 \quad$ USA. Review of Palaeobotany and Palynology, 74, 293-313.

749 Fyfe, R.M., Twiddle, C., Sugita, S. et al. (2013) The Holocene vegetation cover of Britain and Ireland: 750 overcoming problems of scale and discerning patterns of openness. Quaternary Science Reviews, $751 \quad 73,132-148$.

752 Gaillard, M.J., Sugita, S., Bunting, M.J. et al. (2008) The use of modelling and simulation approach 753 in reconstructing past landscapes from fossil pollen data: a review and results from the 754 POLLANDCAL network. Vegetation History and Archaeobotany, 17, 419-443. 
755 Galop, D., Houet, T., Mazier, F. et al. (2011) Grazing activities and biodiversity history in the

756 Pyrenees: New insights on high altitude ecosystems in the framework of a Human-Environment

757 Observatory. Past Global Changes Magazine, 19, 53-55.

758 Galop, D., Rius, D., Cugny, C. et al. (2013) Long-term human-environment interactions history in

759 the French Pyrenean Mountains inferred from pollen data. In: Lozny, L. (ed.) Continuity and

760 Change in Cultural Adaptation to Mountain Environments. Studies in Human Ecology and

761 Adaptation 7. Springer Science + Business Media, New York, pp. 19-30.

762 Herrault, P.A., Larrieu, L., Cordier, S. et al. (2016) Combined effects of area, connectivity, history

763 and structural heterogeneity of woodlands on the species richness of hoverflies (Diptera:

764 Syrphidae). Landscape Ecology, 31, 877-893.

765 Hjelle, K.L. \& Sugita, S. (2012) Estimating pollen productivity and relevant source area of pollen

766 using lake sediments in Norway: how does lake size variation affect the estimates? The Holocene,

$767 \quad 22,313-324$.

768 Hjelle, K.L., Mehl, I.K., Sugita, S. et al. (2015) From pollen percentage to vegetation cover:

769 evaluation of the Landscape Reconstruction Algorithm in western Norway. Journal of Quaternary

$770 \quad$ Science, 30, 312-324.

771 Hjelle, K.L., Halvorsen, L.S., Prøsch-Danielsen, L. et al. (2018) Long-term changes in regional

772 vegetation cover along the west coast of southern Norway: The importance of human impact. 
774 Houet, T., Vacquié, L., Vidal, F. et al. (2012) Caractérisation de la fermeture des paysages dans les 775 Pyrénées depuis les années 1940. Application sur le Haut-Vicdessos. Sud-Ouest européen, 33, 4177656.

777 Houet, T., Vacquié, L. \& Sheeren, D. (2015) Evaluating the spatial uncertainty of future land 778 abandonment in a mountain valley (Vicdessos, Pyrenees-France): insights form model 779 parameterization and experiments. Journal of Mountain Science, 12, 1-18.

780 IPCC, 2014: Climate Change 2014: Synthesis Report. Contribution of Working Groups I, II and III 781 to the Fifth Assessment Report of the Intergovernmental Panel on Climate Change [Core Writing 782 Team, R.K. Pachauri and L.A. Meyer (eds.)]. IPCC, Geneva, Switzerland, 151 pp.

783 Jackson, S.T. \& Lyford, M.E. (1999) Pollen dispersal models in Quaternary plant ecology: 784 assumptions, parameters, and prescriptions. The Botanical Review, 65, 39-75.

785 Kozak, J., Gimmi, U., Houet, T. \& Bolliger, J. (2017) Current practices and challenges for modelling 786 past and future land use and land cover changes in mountainous regions. Regional Environmental Change, 17, 2187-2191.

Kuparinen, A., Markkanen, T., Riikonen, H. et al. (2007) Modeling air-mediated dispersal of spores, pollen and seeds in forested areas. Ecological Modelling, 208, 177-188. 
791 Marboré Lake sequence (2612 m a.s.l., Central Pyrenees, Spain): Testing high altitude sites 792 sensitivity to millennial scale vegetation and climate variability. Global and Planetary Change, $793 \quad 157,214-231$.

794 Leunda, M., González-Sampériz, P., Gil-Romera, G. et al. (2019) Ice cave reveals environmental 795 forcing of long-term Pyrenean tree line dynamics. Journal of Ecology, 107, 814-828.

796 Mariani, M., Connor, S., Theuerkauf, M. et al. (2016) Testing quantitative pollen dispersal models in 797 animal-pollinated vegetation mosaics: An example from temperate Tasmania, Australia. 798 Quaternary Science Reviews, 154, 214-225.

799 Mariani, M., Kuneš, P. Connor, S.E. et al. (2017) How old is the Tasmanian cultural landscape? A 800 test of landscape openness using quantitative land-cover reconstructions. Journal of Biogeography, $80144,2410-2420$.

802 Markgraf, V. (1980) Pollen Dispersal in a Mountain Area. Grana, 19, 127-146.

803 Marquer, L., Gaillard, M.J., Sugita, S. et al. (2014) Holocene changes in vegetation composition in 804 northern Europe: why quantitative pollen-based vegetation reconstructions matter. Quaternary $805 \quad$ Science Reviews, 90, 199-216.

806 Marquer, L., Gaillard, M.J., Sugita, S. et al. (2017) Quantifying the effects of land-use and climate 807 on Holocene plant composition and vegetation change in Europe. Quaternary Science Reviews, $808 \quad 171,20-37$. 
Mazier, F., Gaillard, M.J., Kuneš, P. et al. (2012) Testing the effect of site selection and parameter setting on REVEALS-model estimates of plant abundance using the Czech Quaternary Palynological Database. Review of Palaeobotany and Palynology, 187, 38-49.

Mazier, F., Broström, A., Bragée, P. et al. (2015) Two hundred years of land-use change in the South Swedish Uplands: comparison of historical map-based estimates with a pollen-based reconstruction using the landscape reconstruction algorithm. Vegetation History and Archaeobotany, 24, 555-570.

816 Ortu, E., Brewer, S. \& Peyron, O. (2006) Pollen-inferred palaeoclimate reconstructions in mountain 817 areas: problems and perspectives. Journal of Quaternary Science, 21, 615-627.

818 Overballe-Petersen, M.V., Nielsen, A.B. \& Bradshaw, R.H.W. (2013) Quantitative vegetation reconstruction from pollen analysis and historical inventory data around a Danish small forest hollow. Journal of Vegetation Science, 24, 755-771.

821 Poska, A., Saarse, L., Koppel, K. et al. (2014) The Verijärv area, South Estonia over the last millennium: a high resolution quantitative land cover reconstruction based on pollen and historical data. Review of Palaeobotany and Palynology, 207, 5-17.

824 Prentice, I.C. (1985) Pollen representation, source area, and basin size: toward a unified theory of 825 pollen analysis. Quaternary Research, 23,76-86.

826 Prentice, I.C. (1988) Records of vegetation in time and space: the principles of pollen analysis. In: 
Quintana-Seguí, P., Le Moigne, P., Durand, Y. et al. (2008) Analysis of Near-Surface Atmospheric Variables: Validation of the SAFRAN Analysis over France. Journal of Applied Meteorology and Climatology, 47, 92-107.

Randall, P.M. (1990) A study of modern pollen deposition, Southern Alps, South Island, New

833 Simonneau, A., Chapron, E., Courp, T. et al. (2013) Recent climatic and anthropogenic imprints on 834 lacustrine systems in the Pyrenean Mountains inferred from minerogenic and organic clastic 835 supply (Vicdessos valley, Pyrenees, France). The Holocene, 23, 1762-1775.

836 Stuart, A. \& Ord, J.K. (1994) Kendall's advanced theory of statistics. Volume 1. Distribution theory. $837 \quad$ Edward Arnold.

838 Sugita, S. (1993) A model of pollen source area for an entire lake surface. Quaternary Research, 39, 839 239-244.

840 Sugita, S. (1994) Pollen representation of vegetation in Quaternary sediments: Theory and method in 841 patchy vegetation. Journal of Ecology, 82, 881-897.

842 Sugita, S. (2007a) Theory of quantitative reconstruction of vegetation I: Pollen from large sites 843 REVEALS regional vegetation composition. The Holocene, 17, 229-241.

844 Sugita, S. (2007b) Theory of quantitative reconstruction of vegetation II: All you need is LOVE. The 
846 Sugita, S. (2013) Pollen methods and studies, POLLSCAPE Model: Simulation Approach for Pollen 847 Representation of Vegetation and Land Cover. In: Scott A. Elias (Ed) Encyclopedia of Quaternary 848 Science (Second Edition). Elsevier, Amsterdam, pp. 871-879.

849 Sugita, S., MacDonald, G.M. \& Larsen, C.P.S. (1997) Reconstruction of fire disturbance and forest 850 succession from fossil pollen in lake sediments: potential and limitations. In: Clark, J.S., Cachier, 851 H. et al. (Eds.) Sediment Records of Biomass Burning and Global Change. Springer, Berlin, pp. $852 \quad 387-412$.

853 Sugita, S., Gaillard, M.J. \& Broström, A. (1999) Landscape openness and pollen records: a simulation 854 approach. The Holocene, 9, 409-421.

855 Sugita, S., Hicks, S. \& Sormunen, H. (2010) Absolute pollen productivity and pollen-vegetation 856 relationships in northern Finland. Journal of Quaternary Science, 25, 724-736.

857 Sutton, O.G. (1953) Micrometeorology. McGraw-Hill.

858 Szczypta C., Gascoin S., Houet T., Vigneau C. \& Fanise P. (2015) Impact of climate and land cover 859 changes on snow cover in a small Pyrenean catchment. Journal of Hydrology, 521, 84-99.

860 Theuerkauf, M., Kuparinen, A. \& Joosten, H. (2013) Pollen productivity estimates strongly depend 861 on assumed pollen dispersal. The Holocene, 23, 14-24.

862 Theuerkauf, M., Couwenberg, J., Kuparinen, A. et al. (2016) A matter of dispersal: REVEALSinR 
863 introduces state-of-the-art dispersal models to quantitative vegetation reconstruction. Vegetation

864 History and Archaeobotany, 25, 541-553.

865 Trondman, A.K., Gaillard, M.J., Mazier, F. et al. (2015) First pollen-based quantitative

866 reconstructions of Holocene regional vegetation cover (plant functional types and land-cover

867 types) in Europe suitable for climate modelling. Global Change Biology, 21, 676-697.

868 Trondman, A.K., Gaillard, M.J., Sugita, S. et al. (2016) Are pollen records from small sites 869 appropriate for REVEALS model-based quantitative reconstructions of past regional vegetation?

870 An empirical test in southern Sweden. Vegetation History and Archaeobotany, 25, 131-151.

871 Tutin, T.G., Heywood, V.H., Burgess, N.A. et al. (1964-1980) Flora Europaea. Cambridge 872 University Press: Cambridge, UK.

873 Vacquié, L., Houet, T., Sheeren, D. et al. (2016) Adapting grazing practices to limit the reforestation 874 of mountainous summer pastures: A process-based approach. Environmental Modelling \& 875 Software, 84, 395-411.

876 Zhang, Y., Kong, Z., Yang, Z. et al. (2017) Surface Pollen Distribution from Alpine Vegetation in 877 Eastern Tibet, China. Scientific Reports, 7, 586: doi: 10.1038/s41598-017-00625-7. 


\section{APPENDICES}

887 Appendix A. POLLSCAPE simulation and evaluation of the Landscape Reconstruction Algorithm

888 for mountain regions.

889 Appendix B. Dated materials and details on age-depth models of sedimentary archives.

890 Appendix C. Land cover types based on CORINE datasets, CNRS vegetation map and local maps

891 from Houet et al. (2012), and their absolute proportions of the 20 taxa. 


\section{Appendix A. POLLSCAPE simulation and evaluation of the Landscape Reconstruction Algorithm for mountain regions}

\section{A-1. POLLSCAPE simulations (Sugita 1994, 2013; Sugita et al., 1999; Gaillard et al., 2008) and parameter setting}

POLLSCAPE is a simple simulation approach to evaluate factors and mechanisms that affect pollen-vegetation relationships in patchy and heterogeneous landscapes (Sugita, 1994, 2013). Effects on pollen assemblages of various combinations of specific assumptions and conditions can be assessed; those factors include inter-taxonomic differences in productivity and fall speed of pollen, basin size, spatial patterns of plant distribution and land cover, and atmospheric conditions (e.g., wind speed and turbulence that simultaneously influence pollen dispersal and deposition). This modeling approach has been informative to provide plausible scenarios about how pollen assemblages from lakes and mires would reflect the surrounding vegetation (e.g., Sugita et al., 1997, 1999; Bunting et al., 2004; Bunting and Middleton, 2009; Caseldine et al., 2008; Fyfe, 2006; Gaillard et al., 2008; Hellman et al., 2008; Hjelle and Sugita, 2012).

Major basic assumptions and conditions of the POLLSCAPE approach in this study are as follows:

- The sampling basin, either a lake or mire, is a circular opening in the vegetation canopy on a flat two-dimensional plain; heights of source plants for pollen are assumed to be at the ground level.

- Each taxon has a constant pollen productivity in the entire simulated plot.

- Wind above canopy is the dominant agent of pollen transport.

- Wind direction is even in all directions. Accordingly the spatial distribution of source plants for each taxon is described as a function of distance from a point at the center of the basin.

- Pollen dispersal is approximated either by a Gaussian Plume Model (GPM) of small particles from a ground-level source under various atmospheric conditions (Sutton, 1953; Tauber ,1965; Prentice, 1985, 1988; Sugita, 1993, 1994) or by a Lagrangian Stochastic Model (LSM) under more realistic wind-fields and atmospheric turbulence conditions (Kuparinen et al., 2007; Theuerkauf et al., 2016).

- When pollen assemblages from lakes are concerned, Sugita's model (Sugita, 1993) is used for approximation of pollen deposition on the entire lake surface either by the GPM or the LSM.

For the sake of simplicity this simulation study assumes mountain tops and high plateaus as "landscape islands" on a flat two-dimensional terrain $80 \mathrm{~km}$ x $80 \mathrm{~km}$ in size. Wind fields and turbulence in mountain regions are complex in reality; thus, pollen transport is area- and region- 
specific, making it hard to model in a general way. Although the simulated plots with flat terrains are simplistic, it captures the main characteristics of the spatial structure and species composition of plant communities both in high plateaus and the regional vegetation around the Vicdessos valley (Figure la in the main text).

Table A-1 shows the parameter setting for the simulated landscapes, including the mean plant composition in proportion for individual patch types and the matrix in $80 \mathrm{~km} \mathrm{x} 80 \mathrm{~km}$ plots. The Matrix and Patch Type B represent plant communities in lower altitudes including mountain valleys and flat plains. The Matrix is characterized by forests consisted of broadleaved and conifer trees (Fagus, Quercus and Pinus) with small amounts of grasses (Poaceae) and Ericaceous plants (Calluna and other Ericaceae taxa). Patch type B represents Poaceae-dominated unforested/open areas. Patch Type A symbolizes mountain tops that are characterized by Ericaceae plants (including Rhododendron spp. and Vaccinium spp.) with semi-dominant grass and Calluna (heather). Within the areas occupied by Patch Type A, small-patches of two types of heather heathlands are placed to create a localized mosaic of mountain plant communities: Patch Type $\mathrm{C}$ with heather, grass and Ericaceae and Patch Type D with heather, grass, Ericaceae and Pinus. Patch Type A occupies $30 \%$ of the total area in the $80-\mathrm{km} \times 80-\mathrm{km}$ plots, and the Matrix and Patch Type B 50\% and 20\%, respectively. Within the "mountain" areas covered by Patch Type A, Patch Types C and D occupy $20 \%$ and 10\% in area respectively; the rest (i.e. 70\% in mountain area) is characterized by plant composition of Patch Type A. For all the patch types circular-shaped patches are placed randomly without overlap; patch sizes ( \pm SE) for Patch Types A, B, C and D are $314( \pm 15)$ ha, $10( \pm 1)$ ha, $2( \pm 0.2)$ ha and $1( \pm 0.1)$ ha, respectively.

Simulations place different-sized and circular-shaped lakes - $500 \mathrm{~m}$ and $50 \mathrm{~m}$ in radius only in patches of Patch Type A. Pollen data from 500-m radius lakes are used for REVEALS modeling in the LRA (Sugita, 2007a) to estimate the mean vegetation composition within a 100-km radius from the center of individual lakes; those from 50-m radius lakes are applied for LOVE modeling (Sugita, 2007b) to evaluate the relevant source area of pollen (RSAP; sensu Sugita, 1994) and estimate the local vegetation composition within the RSAP. A 500-m radius lake is set at the center of a patch of Patch Type A that is randomly selected in the central part of the plot; we repeat the same process thirty times to obtain thirty sets of pollen loading and proportions independently. For a 50-m radius lake the same sampling scheme is used, except for the location of the lake that is placed randomly within a patch of Patch Type A; then we repeat the process thirty times. Each trial, either for a 500-m radius lake or a 50-m radius lake, is run independently from the other runs. Mean plant abundance (i.e. the area occupied by each plant type per unit area) is calculated in consecutive concentric rings $5-\mathrm{m}$ in width from the lake shore out to $100 \mathrm{~km}$. For plant abundance data beyond the $80 \mathrm{~km}$ x $80 \mathrm{~km}$ plot border, simulations assume the outside-plot vegetation as homogeneous and the plant composition the same as that within the plot for the constituent taxa (the last column in 
Table A-1).

Table A-1. Parameter setting for simulated landscapes

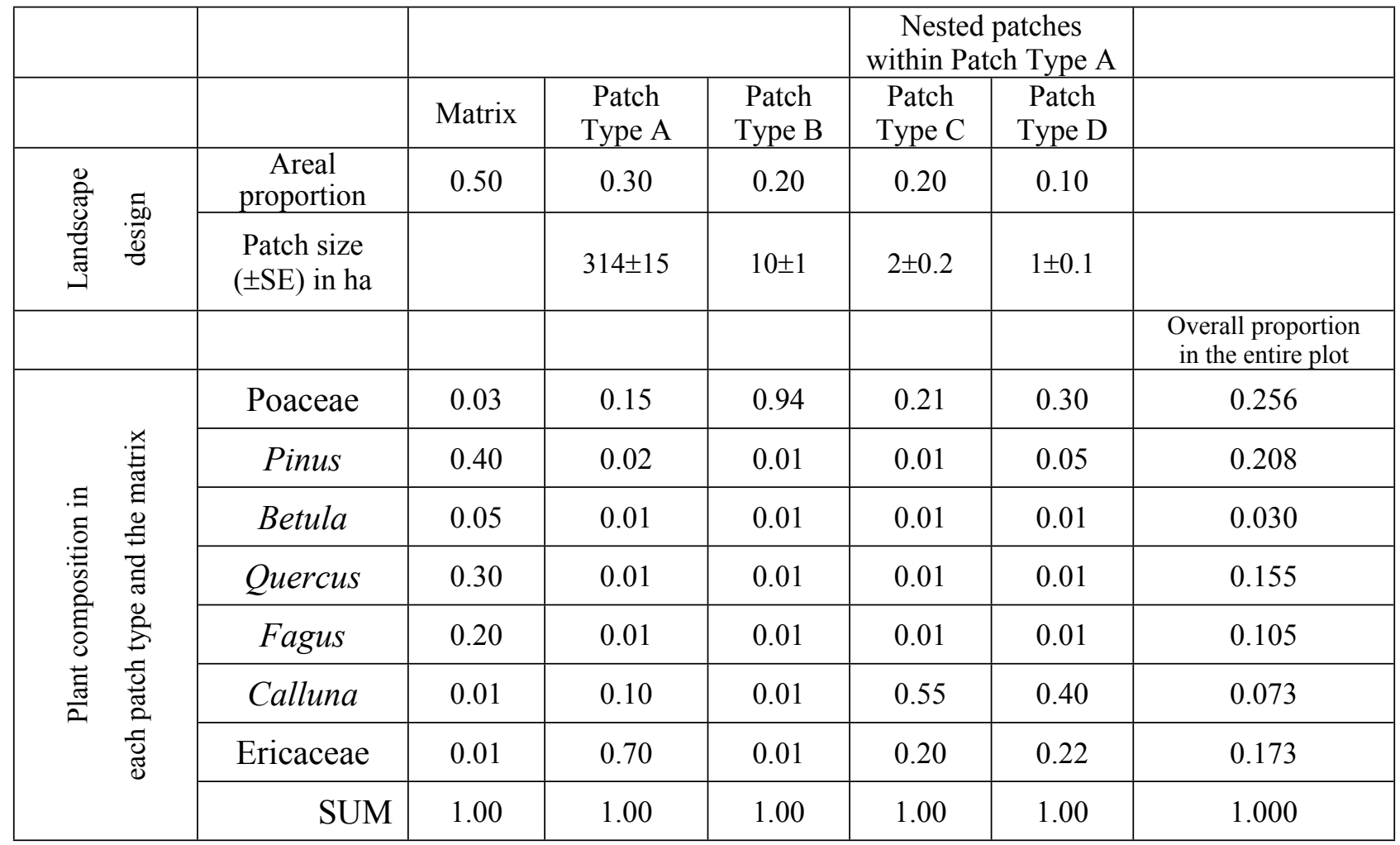

Pollen dispersal and deposition is modeled by both the GPM and LSM options implemented in POLLSCAPE2017.v3.4.exe (Sugita, unpublished). The LSM option uses a look-up table of distance-dependent pollen deposition from a single point source based on the LSM model of Kuparinen et al. (2007) and Theuerkauf et al. (2016); the table was obtained from M. Theuerkauf. This implementation assumes the pollen source area to be within a 100-km radius from each lake. The GPM option, based on Sutton (1953), has been applied in palynology since the 1960s (Tauber, 1965). Those dispersal models are used to obtain the distance-weighted plant abundance (DWPA) of the surrounding vegetation, using the mean plant-abundance data at every $5-\mathrm{m}$ increment out to 100 $\mathrm{km}$ at each site. In theory, pollen loading is linearly related to the DWPA for each of the constituent plant taxa (Prentice, 1985; Sugita, 1993, 1994, 2007a, 2007b); the slope of the relationship represents pollen productivity of the corresponding taxon. Pollen productivity estimates (PPEs) relative to that of Poaceae are listed in Table A-2 (after Mazier et al., 2012). Those estimates were compiled from previous studies in various parts of northwestern Europe (Broström et al., 2008; many others). Those studies cited use the Extended R-Value (ERV) model for obtaining PPEs, assuming that pollen dispersal and deposition follows the GPM (Prentice, 1985; Sugita, 1994). With the LSM option the 
number of European plant/pollen types, for which PPEs are available, is still limited, except for PPEs obtained in Theuerkauf et al. (2013). This study uses the estimates in Table A-2 as inputs to simulation runs with either the GPM or the LSM, for the sake of consistency. Table A-2 also includes estimates of the fall speed of pollen in air - an important parameter for either the GPM or the LSM - for individual taxa (after Mazier et al., 2012).

Table A-2. Relative pollen productivity and fall speed of pollen used in simulations (after Mazier et al., 2012)

\begin{tabular}{|c|c|c|}
\hline & $\begin{array}{c}\text { Relative pollen } \\
\text { productivity }\end{array}$ & $\begin{array}{c}\text { Fall speed of } \\
\text { pollen }\left[\mathrm{m} \mathrm{sec}^{-1}\right]\end{array}$ \\
\hline Poaceae & 1.00 & 0.035 \\
\hline Pinus & 6.38 & 0.031 \\
\hline Betula & 3.09 & 0.024 \\
\hline Quercus & 5.83 & 0.035 \\
\hline Fagus & 2.35 & 0.057 \\
\hline Calluna & 0.82 & 0.038 \\
\hline Ericaceae & 0.07 & 0.038 \\
\hline
\end{tabular}

POLLSCAPE simulations result in pollen proportions of the constituent taxa at each lake, calculated from the pollen loading data relative to that of a reference taxon. Pollen counts are then obtained by back calculation in such a way that the total sum becomes 1000 grains at each site.

\section{A-2. Landscape Reconstruction Algorithm (LRA - Sugita, 2007a, 2007b; Sugita et al., 2010)}

The Landscape Reconstruction Algorithm (LRA) consists of two steps: estimating regional vegetation using the REVEALS model (Sugita, 2007a) and local vegetation using the LOVE model (Sugita, 2007b). REVEALS outcomes provide the mean vegetation composition, not distance weighted, within a 50-100 $\mathrm{km}$ radius. With the REVEALS results as inputs, LOVE calculates the local vegetation composition in a distance-weighted fashion within the relevant source area of pollen (RSAP) - the smallest spatial scale possible for local vegetation reconstruction (Sugita, 1994, 2007b; Sugita et al., 2010). Both the GPM and the LSM options are used for the LRA applications for comparison. Relative PPEs and fall speed of pollen in Table A-2 are entered to all the LRA runs.

All the LOVE-based estimates of local vegetation within the RSAP are obtained using pollen data from lake 50-m in radius. An inverse modeling approach of LOVE (Sugita, 2007b; Sugita 
et al., 2010) is applied for the RSAP estimate for all the LRA runs. The basic assumptions and conditions described in the POLLSCAPE section above are mostly the same for the Landscape Reconstruction Algorithm (LRA) applied in the simulation runs here.

Ideally pollen records from large sites $>100$ ha are preferable for REVEALS applications (Sugita, 2007a). The main conclusions of this simulation study (i.e. Figure 1 in the main text) are drawn from the result based on the REVEALS runs with pollen data from 500-m radius lakes. When large sites are unavailable as in most mountain regions, pollen records from a number of small sites could potentially be used for both the REVEALS and LOVE applications; however, uncertainties of the regional vegetation estimates in particular are expected to increase in unknown ways (Sugita, 2007a; Sugita et al., 2010; Fyfe et al., 2013; Mazier et al., 2015; Trondman et al., 2016).

To evaluate uncertainties and accuracy of the LRA results when pollen records from small sites are used for REVEALS in mountain situations, we conducted additional simulation runs, assuming that the REVEALS estimates of regional vegetation composition are obtained using pollen records from 50-m radius lakes (i.e. those are the same as those created for the LOVE calculations in the main simulation runs). Figure A-1 shows the simulation result.
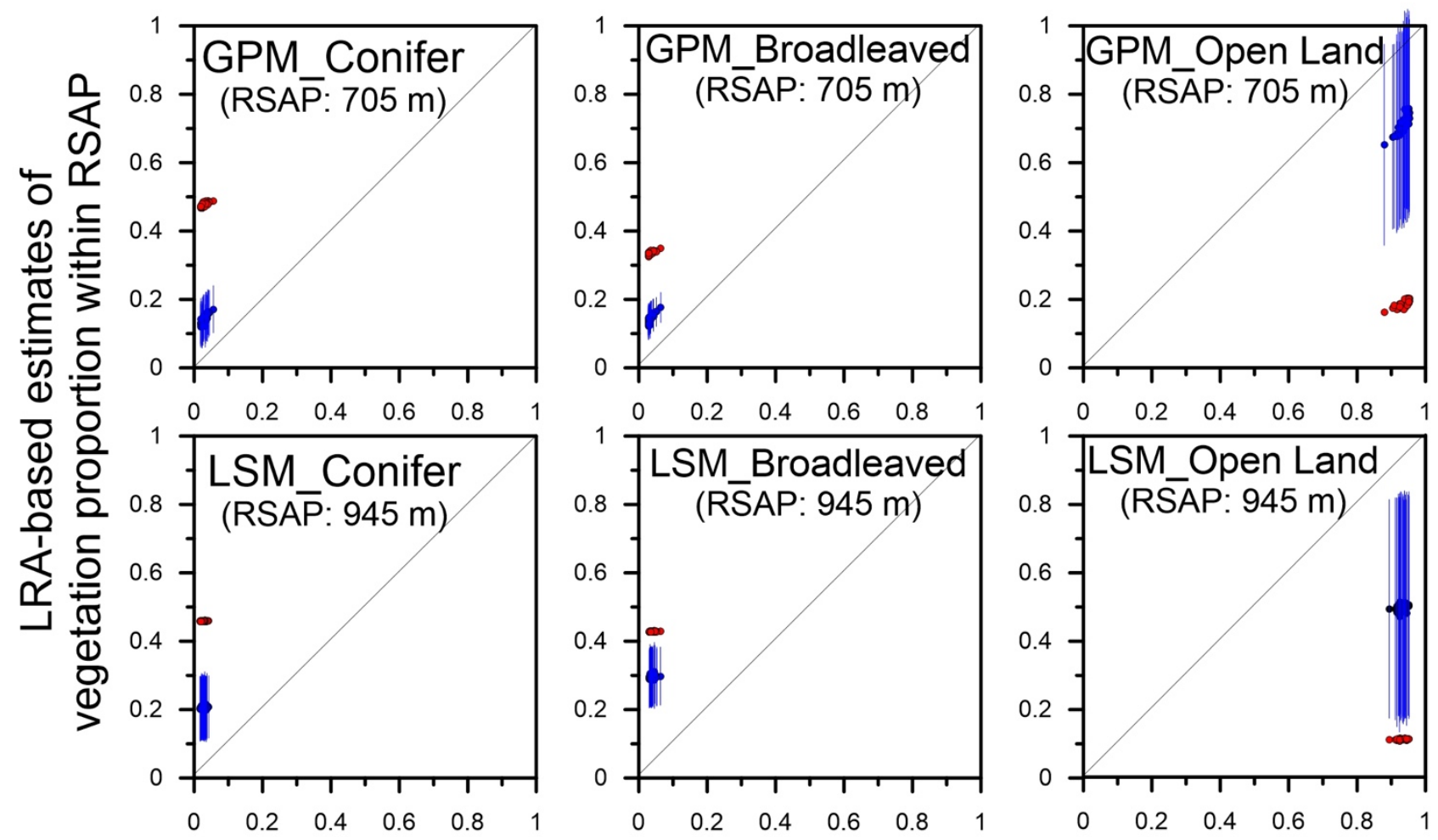

DWPA-based vegetation proportion

Figure A-1. LRA-based estimates of local vegetation against DWPA-based vegetation proportion within RSAP, assuming all the pollen records are from 50-m radius lakes in Patch Type A. Blue dots and error bars indicate the LRA estimates and their SEs against vegetation proportions at 30 sites; red dots represent pollen proportions at 30 sites. RSAP is the area within a 705-m radius when GPM is used and within a 945-m radius when LSM is used. 
When all pollen sites are small lakes 50-m in radius for both the REVEALS and LOVE runs, the accuracy of the LRA results are not as good as those shown in Figure 1-b in the main text. The RSAP estimates become larger than those shown in Figure 1-b: 705 m (GPM) and 945 m (LSM) against $310 \mathrm{~m}$ (GPM) and $325 \mathrm{~m}$ (LSM). Although Figure A-1 indicate that the LRA still improves significantly the accuracy of vegetation reconstruction over pollen percentages alone, the simulation results demonstrate that regional vegetation reconstruction using pollen records from "large sites" is preferred whenever possible to reduce impacts on the LRA results and reliability of the systematic selection of pollen sites only on mountain tops (Sugita, 2007a).

\section{REFERENCES}

Broström, A., Nielsen, A.B., Gaillard, M.J. et al. (2008) Pollen productivity estimates of key European plant taxa for quantitative reconstruction of past vegetation: a review. Vegetation History and Archaeobotany, 17, 461-478.

Bunting, M.J. \& Middleton, R. (2009) Equifinality and uncertainty in the interpretation of pollen data: the Multiple Scenario Approach to reconstruction of past vegetation mosaics. The Holocene, 19, 799-803.

Bunting, M.J., Gaillard, M.J., Sugita, S. et al. (2004) Vegetation structure and pollen source area. The Holocene, 14, 651-660.

Caseldine, C., Fyfe, R.M., Hjelle, K. (2008) Pollen modelling, palaeoecology and archaeology: virtualization and/or visualisation of the past? Vegetation History and Archaeobotany, 17, 543549.

Fyfe, R.M. (2006) GIS and the application of a model of pollen deposition and dispersal: A new approach to testing landscape hypotheses using the POLLANDCAL models. Journal of Archaeological Science, 33, 483-493.

Fyfe, R.M., Twiddle, C., Sugita, S. et al. (2013) The Holocene vegetation cover of Britain and Ireland: overcoming problems of scale and discerning patterns of openness. Quaternary Science Reviews, $73,132-148$.

Gaillard, M.J., Sugita, S., Bunting, M.J. et al. (2008) The use of modelling and simulation approach in reconstructing past landscapes from fossil pollen data: a review and results from the POLLANDCAL network. Vegetation History and Archaeobotany, 17, 419-443.

Hellman, S., Gaillard, M.J., Broström, A. \& Sugita, S. (2008) Effects of the sampling design and selection of parameter values on pollen-based quantitative reconstructions of regional vegetation: a case study in southern Sweden using the REVEALS model. Vegetation History and 
Archaeobotany, 17, 445-459.

Hjelle, K.L. \& Sugita, S. (2012) Estimating pollen productivity and relevant source area of pollen using lake sediments in Norway: how does lake size variation affect the estimates? The Holocene, 22, 313-324.

Kuparinen, A., Markkanen, T., Riikonen, H. et al. (2007) Modeling air-mediated dispersal of spores, pollen and seeds in forested areas. Ecological Modelling, 208, 177-188.

Mazier, F., Gaillard, M.J., Kuneš, P. et al. (2012) Testing the effect of site selection and parameter setting on REVEALS-model estimates of plant abundance using the Czech Quaternary Palynological Database. Review of Palaeobotany and Palynology, 187, 38-49.

Mazier, F., Broström, A., Bragée, P. et al. (2015) Two hundred years of land-use change in the South Swedish Uplands: comparison of historical map-based estimates with a pollen-based reconstruction using the landscape reconstruction algorithm. Vegetation History and Archaeobotany, 24, 555-570.

Prentice, I.C. (1985) Pollen representation, source area, and basin size: toward a unified theory of pollen analysis. Quaternary Research, 23,76-86.

Prentice, I.C. (1988) Records of vegetation in time and space: the principles of pollen analysis. In: Huntley, B. \& Webb, T. (Eds.) Vegetation history. Kluwer, Dordrecht, pp. 17-42.

Sugita, S. (1993) A model of pollen source area for an entire lake surface. Quaternary Research, 39, 239-244.

Sugita, S. (1994) Pollen representation of vegetation in Quaternary sediments: Theory and method in patchy vegetation. Journal of Ecology, 82, 881-897.

Sugita, S. (2007a) Theory of quantitative reconstruction of vegetation I: Pollen from large sites REVEALS regional vegetation composition. The Holocene, 17, 229-241.

Sugita, S. (2007b) Theory of quantitative reconstruction of vegetation II: All you need is LOVE. The Holocene, 17, 243-257.

Sugita, S. (2013) Pollen methods and studies, POLLSCAPE Model: Simulation Approach for Pollen Representation of Vegetation and Land Cover. In: Scott A. Elias (Ed) Encyclopedia of Quaternary Science (Second Edition). Elsevier, Amsterdam, pp. 871-879.

Sugita, S., MacDonald, G.M. \& Larsen, C.P.S. (1997) Reconstruction of fire disturbance and forest succession from fossil pollen in lake sediments: potential and limitations. In: Clark, J.S., Cachier, H. et al. (Eds.) Sediment Records of Biomass Burning and Global Change. Springer, Berlin, pp. 387-412.

Sugita, S., Gaillard, M.J. \& Broström, A. (1999) Landscape openness and pollen records: a simulation approach. The Holocene, 9, 409-421.

Sugita, S., Hicks, S. \& Sormunen, H. (2010) Absolute pollen productivity and pollen-vegetation relationships in northern Finland. Journal of Quaternary Science, 25, 724-736. 
Sutton, O.G. (1953) Micrometeorology. McGraw-Hill.

Tauber, H. (1965) Differential pollen dispersion and the interpretation of pollen diagrams. Danmarks Geologiske Undersøgelse. II. RÆKKE, No. 89: 1-69.

Theuerkauf, M., Kuparinen, A. \& Joosten, H. (2013) Pollen productivity estimates strongly depend on assumed pollen dispersal. The Holocene, 23, 14-24.

Theuerkauf, M., Couwenberg, J., Kuparinen, A. et al. (2016) A matter of dispersal: REVEALSinR introduces state-of-the-art dispersal models to quantitative vegetation reconstruction. Vegetation History and Archaeobotany, 25, 541-553.

Trondman, A.K., Gaillard, M.J., Sugita, S. et al. (2016) Are pollen records from small sites appropriate for REVEALS model-based quantitative reconstructions of past regional vegetation? An empirical test in southern Sweden. Vegetation History and Archaeobotany, 25, 131-151. 


\section{Appendix B. Dated materials and details on age-depth models of sedimentary archives.}

Lake and peat cores were dated by using radiocarbon and ${ }^{210} \mathrm{~Pb}$ ages together. Age-depth models were based on all available age dating information and the entire cores, although the present study focused on the last 60 years. Radiocarbon dating were obtained from previouslyidentified above-ground plant remains selected from $1 \mathrm{~cm}^{3}$ of bulk peat/sediment at EcoLab and GEODE laboratories following Mauquoy et al. (2004). Sample pretreatments included acidalkali-acid washing (to remove bacterial $\mathrm{CO}_{2}$, carbonate and humic-fulvic acids), drying, combustion and graphitization. These pretreatments and the radiocarbon measurements by acceleration mass spectrometer were performed at Beta Analytic (London, UK), Poznan Radiocarbon Laboratory (Poznan, Poland) and ARTEMIS facility (CNRS-Gif sur Yvette, France). ${ }^{210} \mathrm{~Pb}$ measurements were achieved by using peat powder and Gamma spectrometry (Van Beek et al., 2013; Appleby, 2002), except Orry de Théo peatland for which Alpha spectrometry was used (Sanchez-Cabeza et al., 1998).

Table B-1 summarizes the dating information. The age-depth models of Legunabens, Arbu and Fouzes that were not published so far are given below.

Table B-1. Background information about the dating used in this study.

\begin{tabular}{|c|c|c|c|c|c|}
\hline Site name & $\begin{array}{l}\text { Type of } \\
\text { Records }\end{array}$ & ${ }^{14} \mathrm{C}$ Bomb Pulse & ${ }^{210} \mathrm{~Pb}$ & $\begin{array}{l}\text { Number of } \\
{ }^{14} \mathrm{C} \text { ages }\end{array}$ & References \\
\hline Sigriou (SIG) & Lake & & Gamma spec. & $\mathrm{n}=5$ (+ 2 outliers) & Simonneau et al. 2013 \\
\hline Legunabens (LEG) & Lake & 2 & & 3 & this study \\
\hline Arbu (ARBU) & Lake & & Gamma spec. & 3 & this study \\
\hline Escale (ESC) & Peat & & Gamma spec. & 2 & Hansson et al. 2017 \\
\hline Fouzes (FOUZ) & Peat & & Gamma spec. & 0 & this study \\
\hline W1652a (W1652) & Peat & 5 & Gamma spec. & 4 & Hansson et al. 2017 \\
\hline Etang mort (EM) & Peat & & Gamma spec. & 2 & Hansson et al. 2017 \\
\hline Orry de Théo (OT) & Peat & & Alpha spec. & 4 & Galop et al. 2011 \\
\hline
\end{tabular}




\section{LEGUNABENS}

The age-depth model of Legunabens sediment core is based on five radiocarbon measurements from macrofossils. Three radiocarbon ages are calibrated by using the $\mathrm{NH}$ IntCal09 calibration curve. The results from the two upper sediment layers are used as postbomb ages (Goodsite et al., 2001). The Clam age-depth model is shown in figures B-1 and B-2 and all details about radiocarbon measurements are described in Table B-2 below.

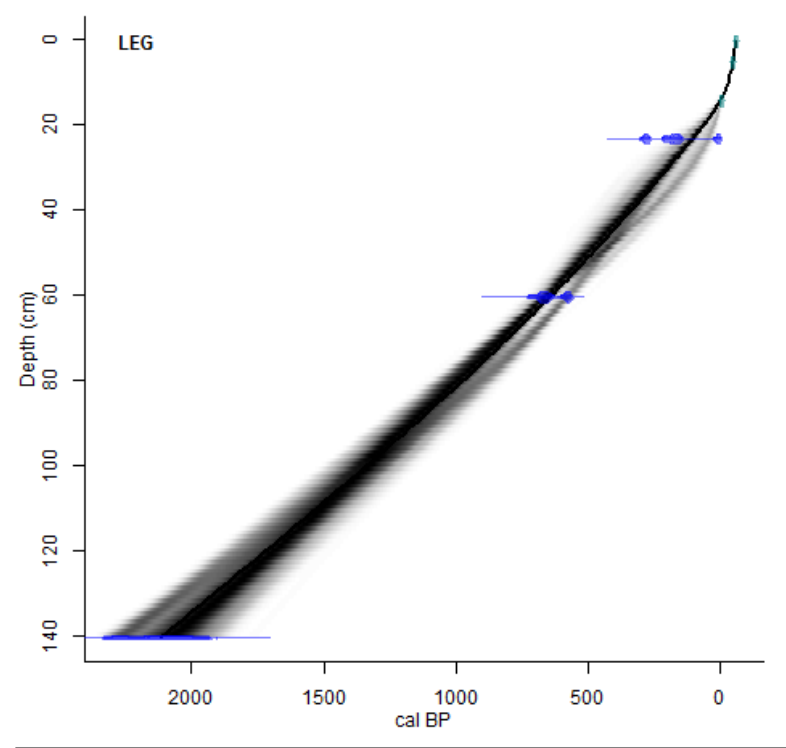

Figure B-1. Clam age-depth model for Legunabens.

Table B-2. Background information about the dating used for Legunabens.

\begin{tabular}{|c|c|c|c|c|}
\hline $\begin{array}{l}\text { Legunabens } \\
\text { Raw } \\
\text { radiocarbon } \\
\text { measurements }\end{array}$ & $\begin{array}{l}\text { Mass } \\
\text { in } \\
\text { grams }\end{array}$ & $\begin{array}{l}\text { Labora } \\
\text { has be }\end{array}$ & $\begin{array}{l}\text { ry label and type of macrofossils that } \\
\text { dated }\end{array}$ & ${ }^{14} \mathrm{C}$ uncal. \\
\hline LG01 05-06 & 5.5 & $\begin{array}{l}\text { Poz- } \\
49543\end{array}$ & Sphagnum leaves and branches, + insect remains & $105.7 \pm 1.08 \mathrm{pMC}$ \\
\hline LG01 14-15 & 14.5 & $\begin{array}{l}\text { Poz- } \\
49578\end{array}$ & Sphagnum leaves and branches, + insect remains & $113.86 \pm 1.23 \mathrm{pMC}$ \\
\hline $\begin{array}{l}\text { LG01 23-24 } \\
\text { CS }\end{array}$ & 23.5 & $\begin{array}{l}\text { Poz- } \\
49576\end{array}$ & Sphagnum leaves and branches, + other mosses sp. & $195 \pm 30$ \\
\hline $\begin{array}{l}\text { LG01 60-61 } \\
\text { CS }\end{array}$ & 60.5 & $\begin{array}{l}\text { Poz- } \\
49575\end{array}$ & $\begin{array}{l}\text { Sphagnum leaves and branches, and some insect } \\
\text { remains }\end{array}$ & $700 \pm 50$ \\
\hline $\begin{array}{l}\text { LG01 140- } \\
141 \text { CS }\end{array}$ & 140.5 & $\begin{array}{l}\text { Poz- } \\
49542\end{array}$ & Leaves of Sphagnum sp. & $2130 \pm 90$ \\
\hline
\end{tabular}




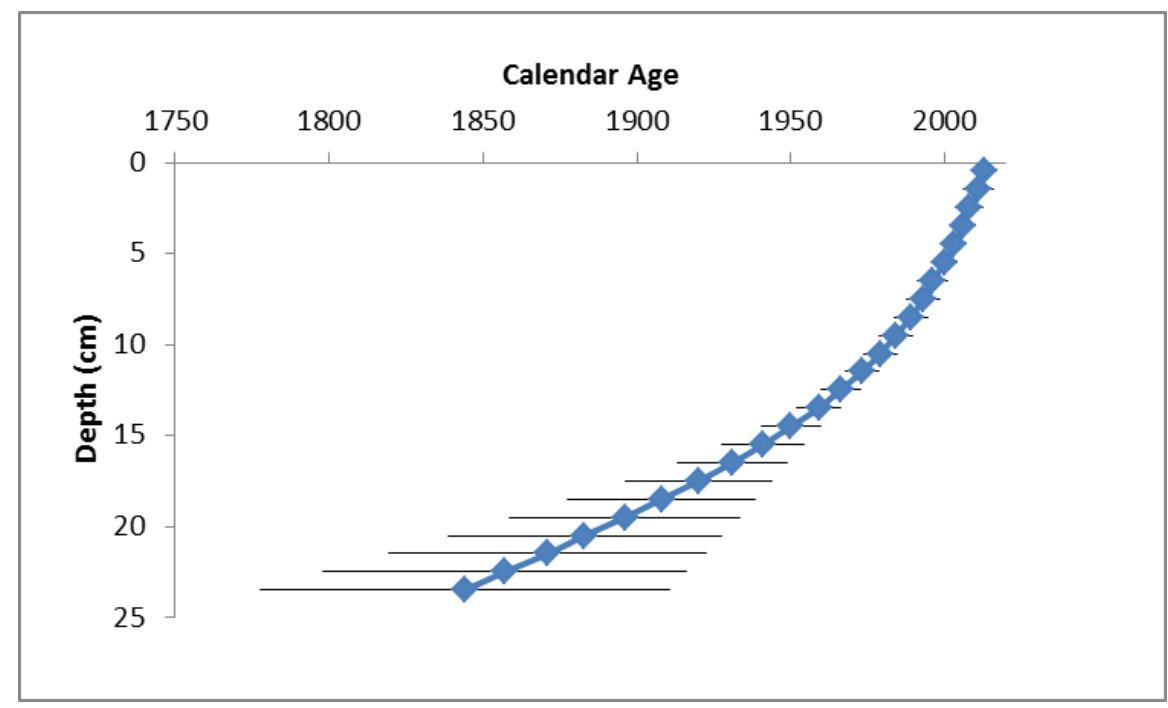

Figure B-2. Zoom on the outcomes of the Clam age-depth model for the upper sediment layers of Legunabens.

\section{FOUZES}

${ }^{210} \mathrm{~Pb}$ and other radionuclides were measured at LAFARA/OMP by gamma Spectrometry (P. Van Beek and M. Souhault) - https://lafara.obs-mip.fr/. Unsupported ${ }^{210} \mathrm{~Pb}$ was estimated using total ${ }^{210} \mathrm{~Pb}$ and ${ }^{226} \mathrm{Ra}\left({ }^{214} \mathrm{~Pb}\right)$ to assess supported ${ }^{210} \mathrm{~Pb}$. Age dating was estimated using the CRS model (Appleby, 2002) and model uncertainties were calculated with MonteCarlo simulations (Binford et al., 1990) based on a Matlab routine written by P.E. Higuera and modified by M. Enrico. The age-depth model was validated by the measurements of a ${ }^{137} \mathrm{Cs}$ peak around 1960 and the detection of ${ }^{241} \mathrm{Am}$ traces at the same time period. The Clam age-depth model is shown in Figure B-3.

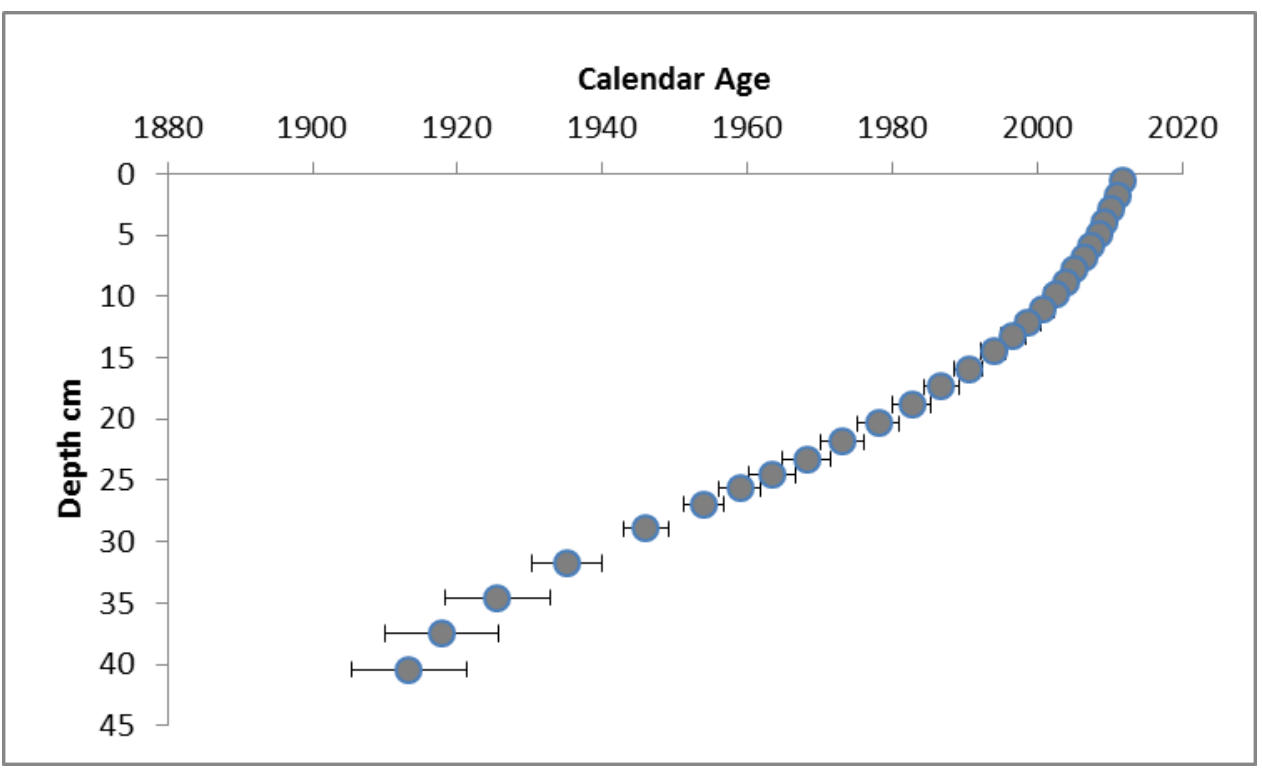

Figure B-3. Clam age-depth model for Fouzes. 


\section{ARBU}

The age-depth model for Arbu sedimentary core is based on a combination of ${ }^{210} \mathrm{~Pb}$ measurements (CRS model; Appleby, 2002) and three radiocarbon age dates. No ${ }^{137} \mathrm{Cs}$ peak was clearly defined, however ${ }^{137} \mathrm{Cs}$ was found in the layer dated after 1950 with an increase until 1960. A clear peak of ${ }^{241}$ Am was found for the sediment slices dated from 1955 to 1975 . The Clam age-depth model is shown in Figure B-4. Figure B-5 corresponds to a zoom on the outcomes of the Clam age-depth model for the upper sediment layers.

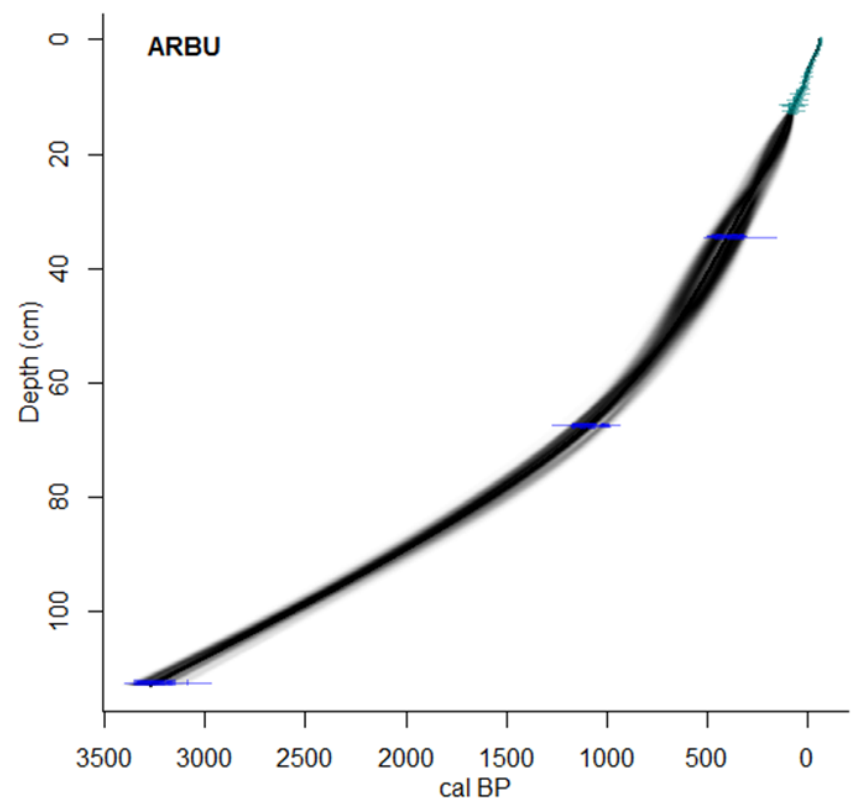

Figure B-1. Clam age-depth model for Arbu.

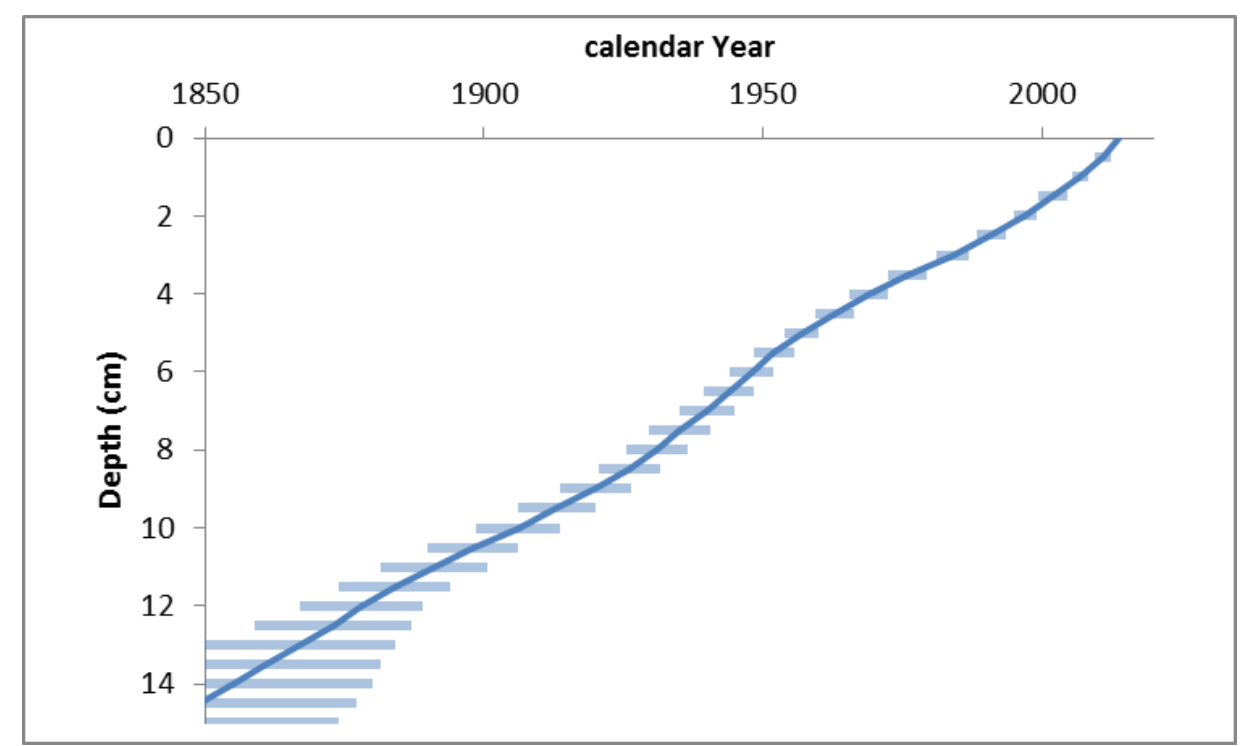

Figure B-2. Zoom on the outcomes of the Clam age-depth model for the upper sediment layers of Arbu. 


\section{REFERENCES}

Appleby, P.G. (2002) Chronostratigraphic techniques in recent sediments. In: Tracking environmental change using lake sediments. Springer, Dordrecht, p. 171-203.

van Beek, P., Souhaut, M., Lansard, B. et al. (2013) LAFARA: A new underground laboratory in the French Pyrénées for low-background gamma spectrometry. Journal of Environmental Radioactivity, 116, 152-158.

Galop, D., Houet, T., Mazier, F. et al. (2011) Grazing activities and biodiversity history in the Pyrenees: New insights on high altitude ecosystems in the framework of a HumanEnvironment Observatory. Past Global Changes Magazine, 19, 53-55.

Goodsite, M.E., Rom, W., Heinemeier, J. et al. (2001) High-resolution AMS 14 C dating of post-bomb peat archives of atmospheric pollutants. Radiocarbon, 43, 495-515.

Hansson, S.V., Claustres, A., Probst, A. et al. (2017) Atmospheric and terrigenous metal accumulation over 3000 years in a French mountain catchment: Local vs distal influences. Anthropocene, 19, 45-54.

Mauquoy, D., Blaauw, M., van Geel, B. et al. (2004) Late Holocene climatic changes in Tierra del Fuego based on multiproxy analyses of peat deposits. Quaternary Research, 61, 148-158.

Sanchez-Cabeza, J.A., Masqué, P. \& Ani-Ragolta, I. (1998) ${ }^{210} \mathrm{~Pb}$ and ${ }^{210} \mathrm{Po}$ analysis in sediments and soils by microwave acid digestion. Journal of Radioanalytical and Nuclear Chemistry, 227, 19-22.

Simonneau, A., Chapron, E., Courp, T. et al. (2013) Recent climatic and anthropogenic imprints on lacustrine systems in the Pyrenean Mountains inferred from minerogenic and organic clastic supply (Vicdessos valley, Pyrenees, France). The Holocene, 23, 1762-1775. 

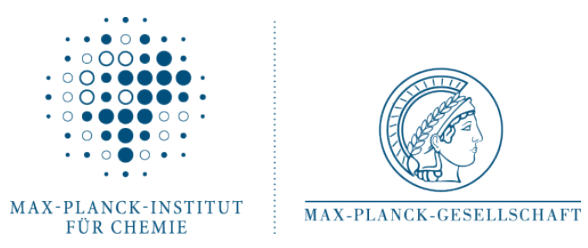

Dr. Laurent Marquer

Research Group for Terrestrial Palaeoclimates

Max Planck Institute for Chemistry, Mainz (Germany)

E-mails: laurent.marquer.es@gmail.com; 1.marquer@mpic.de

To: J. S. Carrion (Editor of Quaternary Science Reviews).

Mainz, October $24^{\text {th }} 2019$

Dear Professor Carrion,

We have no conflict of interest to declare.

Yours sincerely,

Laurent Marquer and the co-authors.

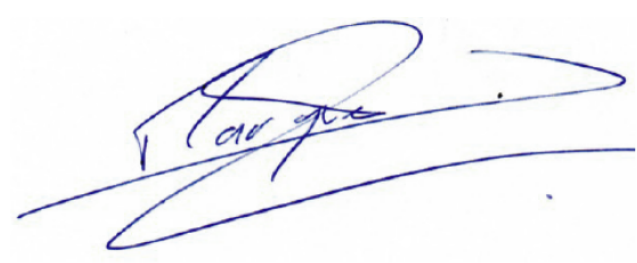




\section{Author contributions}

2 L.M., F.M, S.S. and M.J.G. conceived the initial idea; L.M. ran the LRA model; S.S. led the 3 runs related to the evaluation with simulated landscapes; D.G., F.M. and E.F. provided the

4 pollen data; T.H. provided the local land-cover maps for three time windows; S.H. and 5 N.D.M. provided the plant composition in each land-cover type; A.S., F.D.V. and G.L.R. 6 provided the age-depth models at individual sites. L.M. led analyses and writing with 7 substantial input from F.M. and S.S. All authors contributed to various versions of the 8 manuscript. 